\title{
The Behavioral Ecology of Moral Dilemmas: Childhood Unpredictability, but Not Harshness, Predicts Less Deontological and Utilitarian Responding
}

\author{
Authors \\ Heather M. Maranges \\ Department of Psychology and Social Justice Centre, Concordia University \\ Connor R. Hasty, Jon K. Maner, \& Paul Conway \\ Department of Psychology, Florida State University
}

\begin{abstract}
Author Note
Correspondence concerning this article should be sent to Heather Maranges, Concordia University, Department of Psychology, 7141 Sherbrooke West, Montreal, QC, Canada, H4B 1R6. Phone: (514) 848-2424. Email: heather.maranges@ concordia.ca.

\section{Citation}

Maranges, H. M., Hasty, C., Maner, J. K., \& Conway, P. (2020). The behavioral ecology of moral dilemmas: Childhood unpredictability, but not harshness, predicts less deontological and utilitarian responding. Journal of Personality and Social Psychology. In press.

(C) 2020, American Psychological Association. This paper is not the copy of record and may not exactly replicate the final, authoritative version of the article. Please do not copy or cite without authors' permission. The final article will be available, upon publication, via its DOI:

$10.1037 / \mathrm{pspp} 0000368$
\end{abstract}




\begin{abstract}
Childhood unpredictability and harshness are associated with patterns of psychology and behavior that enable individuals to make the most of adverse environments. The current research assessed effects of childhood unpredictability and harshness on individual differences in sacrificial moral decision making. Six studies $(N=1,503)$ supported the hypothesis that childhood unpredictability, but not harshness, would be associated with fewer decisions to reject harm (consistent with deontological ethics) and to maximize overall outcomes (consistent with utilitarian ethics). These associations were not moderated by perceptions of current environmental unpredictability (Studies 3a and 3b) and were robust to potential confounds (religiosity, political conservativism, Big-5 personality traits, and social desirability; Study 5). The associations between childhood unpredictability and lower deontological and utilitarian tendencies were statistically mediated by low levels of empathic concern and poor-quality social relationships (Study 4). Findings are consistent with the possibility that early calibration to ecological unpredictability, but not harshness, undermines other-oriented psychological processes which, in turn, reduce moral concerns about harm and consequences for other people. Keywords: childhood unpredictability, childhood harshness, behavioral ecology, moral dilemmas, process dissociation
\end{abstract}


Humans display remarkable flexibility, responding adaptively to the challenges and opportunities afforded by their ecologies (Neuberg et al., 2010; Pigliucci, 2005; West-Eberhard, 1989). Two crucial ecological affordances that influence a range of cognitive and behavioral processes across the lifespan involve the extent to which one's early childhood environment is unpredictable (i.e., erratic and uncertain) and harsh (i.e., lacking in resources, characterized by high mortality and morbidity). Exposure to unpredictable and harsh environments in childhood has been implicated in a range of long-term outcomes in domains as far-reaching as close relationships, economic decisions, and health (e.g., Doom et al., 2016; Mittal \& Griskevicius, 2014; Szepsenwol et al., 2019; for review, see Pepper \& Nettle, 2017). Yet, little is known about the implications of unpredictability and harshness on a central aspect of social life: morality. The current work investigated links between early developmental exposure to environmental unpredictability and harshness and individual differences in decision making on sacrificial moral dilemmas that pit a desire to avoid causing harm against a desire to maximize others' overall wellbeing.

Childhood unpredictability is associated with individual differences and psychological processes characterized by a focus on the present at the cost of future consequences and on the self at the cost of others (e.g., Belsky et al., 2012; Doom et al., 2016; Jonason et al., 2016; Simpson et al., 2012; Young et al., 2018). Hence, in the context of sacrificial moral dilemmas, people exposed to relatively unpredictable (versus predictable) childhood ecologies may be less likely to concern themselves with avoiding harm to other people and also less likely to strive to maximize people's overall wellbeing. Although some work suggests that, like unpredictability, childhood harshness predicts a focus on the present at the cost of future consequences (e.g., Griskevicius et al., 2011; Mittal \& Griskevicius, 2014), other work suggests that harshness 
encourages interdependence and consideration of the wellbeing of others (e.g., Fiske \& Markus, 2012; Lamont, 2000; Markus et al., 2004). Harshness, then, may not be systematically associated with moral dilemma decision making. Therefore, the overarching prediction guiding the current investigation was that unpredictability, but not harshness, would be associated with weak tendencies to reject harm and maximize outcomes in sacrificial moral dilemmas. We tested this hypothesis in six studies.

\section{Behavioral Ecology: Childhood Unpredictability and Harshness}

Recent advances in behavioral ecology provide an overarching theoretical perspective useful for understanding the effects of childhood ecological variables (e.g., Ellis \& Del Giudice, 2019; Pepper \& Nettle, 2017; Sng et al., 2018). This perspective suggests that affordances encountered early in life calibrate psychological processes in an adaptive manner. ${ }^{1}$ That is, early in development, people learn to behave in a way that is likely to maximize their reproductive fitness in the current environment and that learning processes sets the stage for patterns of behavior throughout the lifespan. Indeed, evidence suggests that early childhood environments fundamentally shape the way people navigate tradeoffs (e.g., between mating and parenting) in a way that helps them make the most of its limited bioenergetic resources (Belsky et al., 1991;

Ellis et al., 2009).

Two key elements of early childhood environments are unpredictability and harshness (Brumbach, Figueredo, \& Ellis, 2009). Unpredictability denotes the extent to which an environment entails erratic or uncertain fluctuations in the presence of threat and/or the availability of resources (Belsky et al., 1991). Harshness denotes the rates of morbidity-mortality

\footnotetext{
${ }^{1}$ It should be noted that, consistent with evolutionary perspectives, we use the term adaptive to mean reproductive fitness-enhancing, rather than to describe behaviors as desirable in a proximate psychological or social sense.
} 
in an organism's environment, largely based on a lack of resources by which to survive; for humans, harshness is closely related to socioeconomic status (SES; Belsky et al., 1991).

Childhood exposure to unpredictability, in particular, has been linked to a range of adaptively calibrated outcomes in adulthood that reflect a focus on the self (versus others) and on the present (versus the future; e.g., Doom et al., 2016; Simpson et al., 2012; Young et al., 2018). Exposure to unpredictable environments suggests that the future is relatively uncertain.

Consequently, childhood unpredictability signals that it would be adaptive to invest primarily in short-term (rather than long-term) biological processes and social/familial relationships (see Pepper \& Nettle, 2017, for a review of the Behavioral Constellation of Deprivation). In contrast, exposure to more predictable environments in childhood suggests that the future is relatively certain and that one can expect a return on investing in long-term biological growth and relationships. For example, early unpredictability is associated with younger age at menarche, sexual debut, first birth, first marriage, and mortality (Chisholm et al., 2005; Xu et al., 2018). Moreover, childhood unpredictability, but not harshness, has been associated with risk taking and risky sexual behavior (Belsky et al., 2012; Simpson et al., 2012).

Unpredictability, but not harshness, prepares the person to accomplish goals and overcome obstacles without support from others, even to the extent of viewing social partners as untrustworthy (Wu et al., 2017) and as a means to an end (e.g., Jonason et al., 2016). For example, unpredictability has been shown to predict greed (Chen, 2018) as well as Machiavellianism and narcissism, whereas harshness has been linked to lower levels of those (Jonason et al., 2016). In extreme cases, unpredictability (but not harshness) predicts a tendency to engage in interpersonal violence (Barbaro \& Shackelford, 2019; Doom et al., 2016; Szepsenwol et al., 2019). Given the essentially social other-focused nature of moral decision 
making, we thus expected childhood unpredictability to be associated with less other-focused moral decision making, both when it comes to individual and overall wellbeing.

Predictions for how childhood harshness shapes moral decision making are less clear. As in unpredictable environments, harsh environments may encourage impatience and risk taking to obtain resources now versus later (e.g., Griskevicius et al., 2011; Mittal \& Griskevicius, 2014). Such work implies that, like unpredictability, harshness might be associated with less otherfocused moral decisions. Some preliminary support for this prediction is provided by work with the Prosocial Moral Reasoning task (PROM; Zhu et al., 2018). The PROM entails reading stories and deciding how the protagonist should behave when facing a moral decision and why she should behave that way (Carlo et al., 1992). The reasons provided to participants track whether they (a) desire to help others and (b) prefer self-focused versus other-focused reasons for helping (Eisenberg, 1986). People who experienced more, versus less, unpredictable and harsh childhoods made more selfish decisions, and this was accounted for by reduced future-oriented planning and reduced emotional attachment (Zhu et al., 2018). Therefore, it is plausible that childhood unpredictability and harshness have similar impacts on sacrificial decisions.

However, there is reason to think that unpredictable and harsh environments beget different patterns of moral decision making. Crucially, their downstream effects on social life diverge: unlike an unpredictable ecology, a harsh ecology renders maladaptive behaviors that benefit the self at the cost of others. Harsh but predictable environments (i.e., those consistently lacking in resources) require investment in social relationships that are enduring and highly interdependent. Enduring relationships provide a social support network that help people work through times of hardship (e.g., Sugiyama, 2004), which may be chronic in harsher ecologies. Indeed, people from lower socioeconomic environments spend more time with family and 
provide more hands-on caregiving to group members (e.g., Markus et al., 2004). Moreover, childhood harshness has been associated with norms of attending and responding to others' needs, connecting to others, and being part of a community (Fiske \& Markus, 2012; Lamont, 2000). This is consistent with studies documenting high levels of social interdependence and prioritization of others among low-socioeconomic status individuals, who tend to lack resources and thus benefit from a consistent give-and-take of social support (Grossmann \& Varnum, 2011; Stephens et al., 2007, 2011, 2012; see also Markus \& Kitayama, 1991). Hence, we may expect that people whose early development occurred in a harsh (but predictable) ecology to be more other-focused in moral decision making.

In sum, although childhood unpredictability and harshness may both predict a focus on the now at the cost of the future, their downstream social effects are likely to diverge. Childhood unpredictability promotes less concern for others, whereas childhood harshness promotes more concern for others. Accordingly, we predicted that childhood unpredictability, but not harshness, would be associated with less other-focused moral decision making in scenarios that entail tradeoffs between harm and the greater good-i.e., moral dilemmas.

\section{Sacrificial Moral Dilemmas}

Sacrificial moral dilemmas are ethical conundrums in which causing harm minimizes total suffering, such as the famous trolley dilemma in which killing one person will save five others (Foot, 1967). Theorists claim that decisions on sacrificial dilemmas align with two philosophical positions: accepting harm to maximize outcomes violates deontological ethics but upholds utilitarian ethics (e.g., Greene et al., 2004). Deontological ethics describe the morality of actions in terms of their intrinsic nature, so causing harm is wrong regardless of the consequences (Kant, 1785/1959). In contrast, utilitarian (or more broadly, consequentialist) 
ethics describe the morality of actions in terms of their overall utility (consequences), so causing harm is acceptable if it improves wellbeing in aggregate (e.g., more lives are saved than lost; Mill, 1861/1998). Researchers may thus descriptively refer to dilemma decisions to avoid causing harm as deontological and to maximize outcomes as utilitarian, though lay people's dilemma decisions are not necessarily driven by such philosophical ideals (see Kahane et al., 2015; Conway et al., 2018).

Dilemma responses reflect a confluence of cognitive and emotional psychological processes. Greene and colleagues (e.g., 2007, 2014) proposed a dual process model suggesting that emotional aversion to harming other people underpins decisions to reject causing harm, whereas cognitive deliberation about consequences underpins decisions to maximize outcomes. ${ }^{2}$ Viewing harm as an inappropriate course of action, even when it would benefit countless people or save lives (consistent with deontological ethics), appears to partially result from negative emotional reactions to harm and emotional concern for others (e.g., Fleischmann et al., 2019). Indeed, deontological responding increases when individuals experience other-focused emotions (Strohminger et al., 2011) or vividly imagine harm (Bartels, 2008; Petrinovich \& O’Neill, 1996). In contrast, deontological responding decreases when harm is trivialized or the emotional distance to victims increases (Petrinovich et al., 1993; Valdesolo \& DeSteno, 2006), emotional processing is dampened (Patil \& Siliani, 2014), or it is difficult to visualize the harm (Amit \& Greene, 2012). Individual differences characterized by a lack of concern for others-lower moral identity, moral conviction about harm, and aversion to others' suffering, and higher psychopathy, egoism, and willingness to commit ethical violations - predict less deontological dilemma

\footnotetext{
${ }^{2}$ An earlier 'hard' version of the dual-process model focused on response speed and efficiency was debunked (e.g., Koop, 2013), but evidence remains for this 'soft' version focused on affect/cognition (Skitka \& Conway, 2018).
} 
responding (Conway et al., 2018; Reynolds \& Conway, 2018; Conway \& Gawronski, 2013; Gawronski et al., 2017).

Viewing harm that increases overall wellbeing (consistent with utilitarian ethics) as acceptable appears to emerge in part from processes that facilitate concern about and consideration of outcomes for the group. Utilitarian responding is positively associated with the motivation (e.g., Bartels, 2008; Nichols \& Mallon, 2006) and capacity (e.g., Baron et al., 2012; Bartels, 2008; Moore et al., 2008; Rozyman et al., 2015) to reflect on how consequences will affect multiple other people. Moreover, utilitarian response tendencies are associated with concern for and willingness to act on behalf of the group (Conway et al., 2018a; Reynolds \& Conway, 2018). Individual differences characterized by a lack of concern for others-lower moral identity, moral conviction about harm, and aversion to witnessing others' suffering, and higher psychopathy, egoism, and willingness to commit ethical violations - also predict less utilitarian dilemma responding (Conway et al., 2018; Reynolds \& Conway, 2018; Conway \& Gawronski, 2013; Gawronski et al., 2017). Finally, some work finds that empathic concern contributes to utilitarian decisions that increase overall wellbeing and decrease overall suffering (e.g., Fleischman et al., 2019; Maranges et al., 2020a, 2020b).

\section{Childhood Unpredictability, Harshness, and Moral Dilemmas: Predictions}

Deontological and utilitarian dilemma responses are guided predominantly by emotional concern for others and consideration of future consequences, particularly for the group, respectively. Moreover, both decisions to reject and accept harm are associated with tendencies to attend to and invest in the wellbeing of others. Childhood unpredictability (vs. predictability), is associated with traits and behaviors characterized by less consideration of future consequences for the self and the group as well as less concern for and investment in sustaining and protecting 
long-term social relationships. Hence, we hypothesized that childhood unpredictability would be negatively associated with both deontological and utilitarian responses on moral dilemmas.

The current investigation also focused on variables that might mediate the hypothesized relationship between childhood unpredictability and moral decisions. Prior work demonstrates that adaptive calibration to early unpredictability entails more less other-focused emotional and interpersonal processes - processes that also predict lower deontological response tendencies (e.g., Conway \& Gawronski, 2013). For example, unpredictability has been associated with lower empathy, perspective taking, and support given to and received from close others, and higher levels of social detachment, antagonism, and psychopathy (e.g., Figueredo et al., 2007; Jonason et al., 2016, 2017; Zhu et al., 2018). Early ecological unpredictability is also associated with less concern for and investment in the future and the group, which predicts lower utilitarian response tendencies (e.g., Conway et al., 2018a; Reynolds \& Conway, 2018). For instance, unpredictability has been associated with more risk taking and impulsivity (Doom et al., 2016) as well as less other-focused moral decision making (Zhu et al., 2018). Hence, we hypothesized that the association between childhood unpredictability and low levels of deontological and utilitarian responses on sacrificial moral dilemmas might be mediated by a lack of trust, emotional concern, and connectedness to other people.

Predictions for harshness were less clear than those for unpredictability. On one hand, effects of harshness sometimes are aligned with those of unpredictability. For example, in one investigation of moral decisions, both childhood unpredictability and harshness were associated with less other-focused decisions, and those associations were mediated through low levels of perspective taking and empathic concern (Zhu et al., 2018). This would suggest that, like unpredictability, harshness may be related to less deontological and utilitarian decision making. 
On the other hand, research on low SES communities suggests that chronic experiences with resource scarcity in childhood result in high, rather than low, levels of empathy, interdependence, and investment in the group's future (e.g., Stephens et al., 2012). This would suggest that harshness may be associated with relatively higher levels of deontological and utilitarian decisions. The current studies carefully disentangled unpredictability from harshness, and thus allowed us to adjudicate between these possible patterns associated with harshness. To test the relationships between unpredictability and harshness and both deontological and utilitarian dilemma responses simultaneously, we employed process dissociation (PD), which provides separate estimates of deontological and utilitarian response tendencies to moral dilemmas. (For additional background and details on PD, please see Supplemental Materials.)

\section{The Current Work}

Across six studies, we tested the prediction that childhood unpredictability, but not harshness, will be associated with less harm-rejecting (deontological) and less outcomemaximizing (utilitarian) responding on sacrificial moral dilemmas. In Study 1, we measured childhood unpredictability and childhood harshness and responses to twenty moral dilemmas. Study 2 entailed a replication and extension of the first study, including an extended measure of childhood harshness. In Studies 3a and 3b (preregistered), we tested whether the effect of childhood unpredictability on moral decision making might shift based on perceptions of current environmental unpredictability. In Study 4 (preregistered), we tested whether multiple candidate mediators - empathic control, general trust, belief in a dangerous world, and relationship network support quality — partially account for the relationships between childhood unpredictability and harm-avoiding (deontological) and outcome-maximizing (utilitarian) dilemma response tendencies. In Study 5 (preregistered), we employed novel, extended measures 
of childhood harshness and unpredictability, including social and physical sources of unpredictability. Furthermore, Study 5 explored the role of potential confounds, including religiosity, conservatism, personality, and social desirability. Across all studies, we report all measures, conditions, and exclusions, and followed APA and our institution's IRB ethical guidelines. ${ }^{3}$

\section{Study 1}

Study 1 tested the prediction that childhood unpredictability, but not harshness, would be associated with less harm avoidance and outcome maximization across sacrificial moral dilemmas.

\section{Method}

Participants. Power analysis indicated that a sample of 207 participants provides $90 \%$ power to detect effects of $r=.20$ (Faul et al., 2007), which is between a small and medium effect size and approximates a common effect size in the dilemma literature (e.g., Conway \& Gawronski, 2013; Conway et al., 2018). Given high rates of attention check and dilemma completion failures and to increase our power, we planned a priori to collect data from at least 350 people. We received responses from three hundred and sixty-one people via Amazon's Mechanical Turk in a single wave. We decided a priori to exclude participants who failed an attention check ( $n=106$; see Oppenheimer et al., 2009) or who failed to answer all dilemmas ${ }^{4}(n$ $=16,15$ of whom also failed the attention check). Our final sample included 254 individuals

\footnotetext{
${ }^{3}$ IRB approval: Florida State University Institutional Review Board, Self-Control and Moral Decision Making 2019.27154, Clarifying Difficult Judgments 2018.26256

${ }^{4}$ Process dissociation calculations typically entail computing percentages out of 10 possible responses, so including participants who complete fewer than all dilemmas can result in calculation problems (see Conway \& Gawronski, 2013, Appendix B).
} 
(120 females, 132 males, 2 other; $M_{\text {age }}=36.02, S D=11.05 ; 194$ White, 38 Black, 16 Hispanic or Latino, 8 Native American, 3 Asian, 2 Pacific Islander).

Procedure and materials. After providing consent, participants completed the moral dilemma battery and measures of childhood unpredictability and harshness before reporting demographics. ${ }^{5}$

Childhood unpredictability. Participants reported whether their childhood environments (i.e., before the age of 10) were characterized by unpredictability using a measure developed by Mittal et al. (2015). Participants rated the extent to which they agreed on a 1 (strongly disagree) to 7 (strongly agree) scale with 8 items, including My family life was generally inconsistent and unpredictable from day-to-day, My parent(s) frequently had arguments or fights with each other or other people in my childhood, My parents had a difficult divorce or separation during this time, People often moved in and out of my house on a pretty random basis, When I woke up, I often didn't know what could happen in my house that day, My family environment was often tense and on edge, Things were often chaotic in my house, and I had a hard time knowing what my parent(s) or other people in my house were going to say. We averaged scores across items and higher scores represent relatively more unpredictable childhood environments $(M=3.83, S D$ $=1.97, \alpha=.96)$.

Childhood harshness. Consistent with previous research (e.g., Belsky et al., 2010; Simpson et al., 2012), we used a measure of family income to index the harshness of participants' childhood environment. Participants responded to the item Think back to your life when you were younger than 10. This time includes preschool, kindergarten, and the first few years of elementary school. What was your family's household income? with options (1) \$15,000

\footnotetext{
${ }^{5}$ In Studies 1, 2, and 3b we also examined how measures of life history strategy would relate to moral dilemma responses. See Supplemental Materials for these measures and analyses.
} 
or less, (2) \$15,001-\$25,000, (3) \$25,001-\$35,000, (4) \$35,001-\$50,000, (5) \$50,001-\$75,000,

(6) $\$ 75,001-\$ 100,000$, (7) $\$ 100,001-\$ 150,000$, and (8) $\$ 150,000$ or more. This item was reverse coded, such that higher values correspond to harsher environments $(M=5.13, S D=1.70)$.

Moral dilemma battery. Participants read and responded to a battery of 10 incongruent and 10 congruent moral dilemmas in a fixed random order (Conway \& Gawronski, 2013; materials and syntax available on Open Science Framework). Each dilemma involved a scenario in which an action produces a harmful outcome, and participants indicated whether each action was appropriate (yes, I find this appropriate) or not (no, I find this inappropriate; Greene et al., 2001). Incongruent dilemmas describe scenarios in which causing harm maximizes overall outcomes, as in conventional sacrificial dilemmas (e.g., Koenigs et al., 2007). For example, participants considered cases in which smothering a crying baby saves the lives of many hiding villagers, a vaccine helps many more than it hurts, and a border guard must decide whether to shoot a traveler before he blows up a checkpoint. In such cases, harm is relatively easy to justify on utilitarian ethical grounds (e.g., killing one target saves multiple lives). Yet, harm remains impermissible according to deontological ethics. Hence, rejecting harm (deontological) and maximizing outcomes (utilitarian) are incongruent response tendencies that motivate opposing judgments.

PD analyses additionally assess responses to the congruent counterpart to each incongruent dilemma. Congruent dilemmas describe identical harmful actions, but the outcome of harm is less beneficial overall. For example, the congruent version of the crying baby dilemmas entails killing a baby to save villagers from manual labor, the congruent vaccine dilemma entails administering a deadly vaccine to prevent a fairly mild flu, and the congruent border crossing entails shooting a traveler to prevent him from working illegally in one's county. 
Such harm is relatively difficult to justify on utilitarian grounds (e.g., killing one person prevents only nonlethal harm), so concerns about rejecting harm and maximizing outcomes are now congruent, leading to the same response. Importantly, there are still amoral or immoral reasons to accept harm on congruent dilemmas, such as sadism or self-interest (e.g., Conway et al., 2018).

By applying responses to both incongruent and congruent dilemmas to a processing tree, researchers can algebraically represent the pathways leading to each response and calculate a Utilitarian parameter (tendency to maximize outcomes regardless of causing harm) and a Deontological parameter (tendency to reject harm regardless of outcomes). This method improves upon use of only conventional judgments (i.e., examining the proportion of harm acceptance for incongruent dilemmas only), which conflate harm avoidance and outcome maximization as inversely related rather than separable. For details on Process Dissociation, parameter calculation, and conventional responses, please see Supplemental Materials.

Demographics and control variables. Participants reported their age, gender, and current family income (with the same response options of the childhood income measure, but not reverse coded, such that higher values indicate higher income, $M=4.40, S D=1.63$ ).

\section{Results}

Data and syntax for all studies are available on the Open Science Framework. First, we tested our primary prediction that childhood unpredictability, but not harshness, would be negatively related to both the $\mathrm{D}$ and $\mathrm{U}$ parameters (see Table 1). Here and for all regression and mediation analyses, we standardized both PD parameters.

Childhood unpredictability. As expected, unpredictability was negatively related to both parameters, such that people who experienced relatively unpredictable childhood environments less often rejected harm and maximized outcomes. These associations held when 
controlling for childhood harshness, adult income, age, gender, and the other parameter: D parameter, $b=-.20, S E=.03, t(243)=-6.31, p<.001, \mathrm{CI}_{95}[-.258,-.135]$, and $\mathrm{U}$ parameter, $b=-$ $.16, S E=.03, t(243)=-4.60, p<.001, \mathrm{CI}_{95}[-.226,-.091]$.

Childhood harshness. Harshness was not related to either PD parameter. These null associations held when controlling for childhood unpredictability, adult income, age, gender, and the other parameter: D parameter, $b=.02, S E=.04, t(243)=.56, p=.579, \mathrm{CI}_{95}[-.052, .093]$, and $\mathrm{U}$ parameter, $b=.02, \mathrm{SE}=.04, t(243)=.58, p=.560, \mathrm{CI}_{95}[-.055, .101]$.

\section{Discussion}

This study is the first to examine links between childhood unpredictability, harshness, and decision making on sacrificial moral dilemmas. As expected, people who experienced a relatively unpredictable childhood environment found harmful actions more acceptable (i.e., less deontological responding) and were less concerned about increasing multiple others' wellbeing (i.e., less utilitarian responding). Childhood harshness was unrelated to moral dilemma decision making - whether people's childhoods were characterized by resource scarcity versus abundance had no bearing on their responses to moral dilemmas. Perhaps, though, our limited measure of harshness (a single item measure of childhood family income) obscured some relationship between resource scarcity and moral decision making - a limitation addressed in Study 2. 
Table 1

Correlations Among Variables, Study 1.

\begin{tabular}{|c|c|c|c|c|c|c|c|}
\hline & 1 & 2 & 3 & 4 & 5 & 6 & 7 \\
\hline $\begin{array}{l}\text { 1. Utilitarian PD } \\
\text { Parameter }\end{array}$ & - & & & & & & \\
\hline $\begin{array}{l}\text { 2. Deontology PD } \\
\text { Parameter }\end{array}$ & $.30^{\star * *}$ & - & & & & & \\
\hline $\begin{array}{l}\text { 3. Childhood } \\
\text { Unpredictability }\end{array}$ & $-.39^{* * *}$ & $-.46^{\star \star \star}$ & - & & & & \\
\hline $\begin{array}{l}\text { 4. Childhood } \\
\text { Harshness }\end{array}$ & -.03 & .03 & $.12^{*}$ & - & & & \\
\hline $\begin{array}{l}\text { 5. Adult } \\
\text { Income }\end{array}$ & .08 & -.01 & $-.17^{\star \star}$ & $-.43^{* \star *}$ & - & & \\
\hline $\begin{array}{l}\text { 6. Gender } \\
(f=1, m=2)\end{array}$ & $-.11^{\dagger}$ & $-.15^{\star}$ & .04 & .08 & .02 & - & \\
\hline 7. Age & $.14^{*}$ & $.28^{\star \star * t}$ & $-.23^{\star \star \star *}$ & $.21^{\star *}$ & .01 & $-.18^{* *}$ & - \\
\hline
\end{tabular}

Note: ${ }^{\dagger} p<.10,{ }^{*} p<.05,{ }^{* *} p<.01,{ }^{* * * *} p<.001$ 


\section{Study 2}

Study 2 entailed a replication of Study 1 with the addition of a longer measure of harshness (Young et al., 2018).

\section{Method}

Participants. Given the high attention check failure rate of Study 1, we sought to increase our sample size for this replication study. We collected data from three hundred and ninety-six people total via Amazon's Mechanical Turk $(n=239)$ and at a large southeastern public university $(n=157)$ in a single wave. As before, we decided a priori to exclude participants who failed an attention check ( $n=135$; Oppenheimer et al., 2009) or who failed to answer all dilemmas ( $n=19$, all of whom also failed the attention check). Our final sample included 261 individuals (148 females, 110 males, 3 other; $M_{\text {age }}=28.29, S D=10.22 ; 206$ White, 28 Black, 28 Hispanic or Latino, 7 Native American, 6 Asian, 5 Pacific Islander, 1 Middle Eastern, 1 Indian, 1 'multi').

Procedure and materials. After providing consent, participants completed the same PD moral dilemma battery and childhood unpredictability measure from Study $1(M=3.01, S D=$ $1.84, \alpha=.94)$. Participants also reported more extensive details about the harshness of their childhood environment by reporting their socioeconomic status (SES): Participants responded to the same item asking about childhood family income as in Study 1, which was reverse coded such that higher scores indicate harsher environments (i.e., fewer resources; $M=4.02, S D=$ 1.96). Additionally, participants rated the extent to which they agreed with three items on a scale from -3 (strongly disagree) to +3 (strongly disagree): My family usually had enough money for things when I was growing up, I grew up in a relatively wealthy neighborhood, and Ifelt relatively wealthy compared with other kids in my school (Mittal et al., 2015, Young et al., 
2018). We converted these responses to 1-7 and reversed them, such that higher scores indicated harsher environments $(M=3.28, S D=1.63)$. All four items were standardized and averaged to create a composite childhood harshness measure $(S D=.86, \alpha=.88)$. As in Study 1, participants also reported demographics and their current family income $(M=5.08, S D=1.98)$.

\section{Results}

First, we tested our primary predictions that childhood unpredictability, but not harshness, would be negatively related to the D and U parameters (see Table 2).

Childhood unpredictability. As expected, and replicating Study 1, unpredictability was negatively related to both PD parameters, such that people who experienced relatively unpredictable childhood environments were less likely to both reject harm and maximize outcomes. These associations held when controlling for childhood harshness, adult income, age, gender, and the other parameter: D parameter, $b=-.14, S E=.04, t(248)=-3.69, p<.001, \mathrm{CI}_{95}[-$ $.207,-.063]$, and U parameter, $b=-.18, S E=.04, t(248)=-5.14, p<.001, \mathrm{CI}_{95}[-.251,-.112]$.

Childhood harshness. Replicating Study 1, harshness was not related to either PD parameter. These null associations held when controlling for childhood unpredictability, adult income, age, gender, and the other parameter: D parameter, $b=.09, S E=.08, t(248)=1.09, p=$ $.277, \mathrm{CI}_{95}[-.072, .250]$, and $\mathrm{U}$ parameter, $b=.14, S E=.08, t(248)=1.76, p=.079, \mathrm{CI}_{95}[-.017$, $.300]$.

\section{Discussion}

Study 2 replicated the link between childhood unpredictability and lower concerns about both rejecting harm and maximizing outcomes on sacrificial moral dilemmas. We also replicated the finding that childhood harshness was not associated with either dilemma response tendency. Together, the findings of Study 2 increased our confidence that early ecologies characterized by 
unpredictability, but not harshness, are associated with individual differences in adult moral decision making. However, it remains unclear how current ecological unpredictability affects these patterns —-we examine this question in Study 3. 
Table 2

Correlations Among Variables, Study 2.

\begin{tabular}{|c|c|c|c|c|c|c|c|}
\hline & 1 & 2 & 3 & 4 & 5 & 6 & 7 \\
\hline $\begin{array}{l}\text { 1. Utilitarian PD } \\
\text { Parameter }\end{array}$ & - & & & & & & \\
\hline $\begin{array}{l}\text { 2. Deontology PD } \\
\text { Parameter }\end{array}$ & $.23^{* * *}$ & - & & & & & \\
\hline $\begin{array}{l}\text { 3. Childhood } \\
\text { Unpredictability }\end{array}$ & $-.39^{* * *}$ & $-.25^{\star \star \star}$ & - & & & & \\
\hline $\begin{array}{l}\text { 4. Childhood } \\
\text { Harshness }\end{array}$ & -.09 & -.03 & $.34^{* * *}$ & - & & & \\
\hline $\begin{array}{l}\text { 5. Adult } \\
\text { Income }\end{array}$ & $.20^{* *}$ & $.12^{\dagger}$ & $-.28^{\star * *}$ & $-.46^{\star \star \star}$ & - & & \\
\hline $\begin{array}{l}\text { 6. Gender } \\
(f=1, m=2)\end{array}$ & $-.10^{\dagger}$ & $-.16^{* *}$ & .10 & $.22^{\star \star * *}$ & $-.18^{\star \star}$ & - & \\
\hline 7. Age & $-.13^{*}$ & $.13^{*}$ & $.21^{\star \star \star}$ & $.28^{* * *}$ & $-.21^{\star \star}$ & .10 & - \\
\hline
\end{tabular}

Note: ${ }^{\dagger} p<.10,{ }^{*} p<.05,{ }^{* *} p<.01,{ }^{* * * *} p<.001$ 


\section{Study 3}

Study 3 had two aims. First, we sought to again replicate the finding that childhood unpredictability, but not harshness, is associated with less utilitarian and deontological decision making on sacrificial moral dilemmas. Second, we examined whether current environmental unpredictability (operationalized as economic unpredictability) moderates these relationships. In prior work, current environmental unpredictability amplified the impact of childhood unpredictability (but not harshness), on measures of cognitive calibration to unpredictability (Mittal et al., 2015; Young et al., 2018). Hence, we expected that for people who experienced relatively unpredictable childhood environments, current unpredictability would lead to even lower levels of deontological and utilitarian response tendencies (i.e., an interaction). It was less clear whether such a manipulation would interact with childhood harshness, which failed to predict moral decision making in the two prior studies. Likewise, we did not have a strong prediction for the main effect of the current unpredictability manipulation on dilemma responses. We tested these predictions in two preregistered studies: Study 3a (aspredicted.org, \#24314) and a more highly powered replication, Study 3b (aspredicted.org, \#24967).

\section{Study 3a}

\section{Method.}

Participants. An a priori power analysis indicated that for the predicted effect size $f=.25$ (medium effect) for the interaction between current and childhood unpredictability, 287 people would be needed to reach $90 \%$ power (Faul et al., 2007). Given expected high rates of attention check failures, we decided to collect data from at least 350 people. We collected data from 376 people via Amazon's Mechanical Turk in a single wave. As preregistered, we decided a priori to exclude participants who failed (a) an attention check ( $n=30$; Oppenheimer et al., 2009), (b) to answer all dilemmas $(n=0)$, or $(\mathrm{c})$ to respond appropriately to the manipulation check (i.e., 
reporting inaccurate information from the current unpredictability slide show; $n=30$ ). Our final sample included 302 individuals (169 females, 132 males, 1 other; $M_{\text {age }}=36.94, S D=11.60 ; 225$ White, 33 Black, 26 Hispanic or Latino, 28 Asian, 5 Native American, 1 Pacific Islander, 1 'mixed,' 1 'Jewish/White').

Procedure and materials. After providing consent, participants viewed a one minute slideshow and responded to the moral dilemma battery, which was interpolated with two manipulation checks/boosters. Then participants responded to the same measures of childhood unpredictability $(M=2.76, S D=1.55, \alpha=.93)$, childhood harshness (items standardized and combined, $S D=.84, \alpha=.86)$, and demographics, including adult income $(M=4.52, S D=1.90)$, as in Study 2.

Current unpredictability manipulation. We employed a manipulation of unpredictability created and used in previous work (Young et al., 2018). We randomly assigned participants to view one of two slideshows ostensibly reporting news headlines from the New York Times. Each slideshow was 60 seconds long, containing 6 slides presented for 10 seconds each. One show was designed to induce a sense of economic unpredictability. The control condition was designed to induce concerns about issues with modern computer technology. Both slideshows included a title page followed by five images coupled with a single sentence of information and were matched on negativity. The economic unpredictability slideshow contained images of and information about a worsening and unpredictable economy, whereas the control slideshow contained images of and information about failures of modern computer technology. See Supplemental Materials for slides. 
Manipulation check and booster. After the $7^{\text {th }}$ and $14^{\text {th }}$ moral dilemmas of the moral dilemma battery, participants reported what information they remembered from the slide show in an open response. This served as our manipulation check and also to boost the manipulation.

Results. First, we tested our predictions that childhood unpredictability is negatively related to both the $\mathrm{U}$ and $\mathrm{D}$ parameters and that current unpredictability will amplify these effects. Second, we examined how childhood harshness would relate to the parameters and explored whether any associations would vary by current unpredictability.

Childhood unpredictability. As expected, and replicating Studies 1 and 2, unpredictability was negatively related to both parameters, such that people who experienced relatively unpredictable childhood environments less often maximized outcomes and avoided harm (see Table 3a). When controlling for childhood harshness, adult income, age, gender, and the other parameter, the association between childhood unpredictability remained significant for the $\mathrm{U}$ parameter and become marginal for the $\mathrm{D}$ parameter: $\mathrm{U}$ parameter, $b=-.12, \mathrm{SE}=.04$, $t(295)=-2.90, p=.004, \mathrm{CI}_{95}[-.197,-.038]$, and D parameter, $b=-.08, S E=.04, t(295)=-1.90, p$ $=.059, \mathrm{CL}_{95}[-.154, .003]$.

Next, we tested whether childhood unpredictability interacted with the current unpredictability manipulation to predict the $\mathrm{U}$ and $\mathrm{D}$ parameters. In two separate regression analyses, we regressed the U parameter or D parameter onto childhood unpredictability (centered), condition (technology fails/control=0, current unpredictability/experimental=1), and their interaction, controlling for the other parameter. The interaction was not significant for either parameter: $\mathrm{U}$ parameter, $b=-.04, \mathrm{SE}=.08, t(297)=-0.50, p=.614, \mathrm{CI}_{95}[-.185, .109]$; D parameter, $b=-.11, S E=.07, t(297)=-1.42, p=.158, \mathrm{CI}_{95}[-.251, .041]$. As we preregistered, we reran the analyses controlling for not only the other parameter, but also childhood harshness, 
adult income, age, and gender. For the $\mathrm{U}$ parameter, the interaction remained nonsignificant, $b=$ $-.03, S E=.07, t(293)=-0.34, p=.734, \mathrm{CI}_{95}[-.171, .120]$. For the D parameter, the interaction was not significant but marginal, $b=-.12, S E=.07, t(293)=-1.66, p=.098, \mathrm{CI}_{95}[-.261, .022] .{ }^{6}$

The economic unpredictability manipulation did not exert a main effect on either the $U$ or D parameter: U parameter, $b=-.15, S E=.12, t(297)=-1.32, p=.189, \mathrm{CI} 95[-.378, .075]$; D parameter, $b=-.14, S E=.12, t(297)=-1.18, p=.239, \mathrm{CI}_{95}[-.462, .091]$. This null effect held when controlling childhood harshness, adult income, age, gender, and the other parameter: U parameter, $b=-.18, S E=.11, t(293)=-1.59, p=.114, \mathrm{CI}_{95}[-.404, .043]$; D parameter, $b=-.11$, $S E=.11, t(293)=-1.00, p=.318, \mathrm{CI}_{95}[-.331, .108]$.

Childhood harshness. Consistent with the prior two studies, childhood harshness was not associated with the D parameter. This held when controlling for childhood unpredictability, adult income, age, gender, and the other parameter, $b=.07, S E=.08, t(295)=0.87, p=.383, \mathrm{CI}_{95}[-$ $.083, .216]$. However, childhood harshness was associated with the U parameter, such that people who experienced relatively harsher (compared with less harsh) childhoods were more likely to maximize outcomes across moral dilemmas. This held when controlling for childhood unpredictability, adult income, age, gender, and the other parameter, $b=.20, S E=.08, t(295)=$ $2.60, p=.010, \mathrm{CI}_{95}[.049, .351]$.

Next, we also explored whether the current economic unpredictability manipulation interacted with childhood harshness to predict moral dilemma decision making. In two separate regression analyses, we regressed the $U$ parameter or D parameter onto childhood harshness

\footnotetext{
${ }^{6}$ Because this interaction was of primary interest, we probed it. However, we caution the reader to keep in mind that it was not statistically different from zero. The interaction indicated that current economic unpredictability (vs. control condition) led to marginally lower harm aversion across moral dilemmas for people who experienced highly unpredictable childhood environments (i.e., $1 \mathrm{SD}$ above the mean of unpredictability), $b=-.30, S E=.16, t(293)=-$ $1.89, p=.060, \mathrm{CI}_{95}[-.602, .012]$, but not for people who experienced highly predictable childhood environments (i.e., $1 \mathrm{SD}$ below the mean of unpredictability), $b=.07, \mathrm{SE}=.16, t(293)=0.46, p=.649, \mathrm{CI}_{95}[-.239, .383]$.
} 
(standardized), condition (technology fails/control=0, current unpredictability/experimental=1), and their interaction, controlling for the other parameter. The interaction was not significant for either parameter: U parameter, $b=-.22, S E=.14, t(297)=-1.59, p=.113, \mathrm{CI}_{95}[-.484, .052]$; D parameter, $b=-.16, S E=.14, t(297)=-1.14, p=.257, \mathrm{CI}_{95}[-.428, .115]$. This pattern of results held when controlling for not only the other parameter, but also childhood unpredictability, adult income, age, and gender: $\mathrm{U}$ parameter, $b=-.20, S E=.14, t(293)=-1.50, p=.134, \mathrm{CI}_{95}[-.470$, $.063]$; D parameter, $b=-.08, S E=.13, t(293)=-0.60, p=.552, \mathrm{CI}_{95}[-.343, .184]$.

Discussion. Study 3a replicated Studies 1 and 2, demonstrating a link between childhood unpredictability and less deontological and utilitarian responding to sacrificial moral dilemmas: People who experienced more unpredictable environments as children were less likely to reject harm and maximize outcomes. As in prior studies, childhood harshness was not associated with deontological response tendencies. New to this study, childhood harshness predicted more utilitarian decision making, suggesting that people whose early ecologies were characterized by resource scarcity were more (not less) sensitive to opportunities to improve outcomes for other people.

Contrary to expectations, the unpredictability of the present environment did not amplify the relationship between childhood unpredictability and moral dilemma response tendencies. Likewise, the current unpredictability manipulation did not moderate links between childhood harshness and deontological or utilitarian response tendencies. However, this study may have been underpowered to detect effects. Hence, to ensure that support for the null hypothesis was not an artifact of sample size, we conducted a preregistered replication of this study with a larger sample. 
Table 3a

Correlations Among Variables, Study $3 a$.

\begin{tabular}{|c|c|c|c|c|c|c|c|c|}
\hline & 1 & 2 & 3 & 4 & 5 & 6 & 7 & 8 \\
\hline $\begin{array}{l}\text { 1. Utilitarian PD } \\
\text { Parameter }\end{array}$ & - & & & & & & & \\
\hline $\begin{array}{l}\text { 2. Deontology PD } \\
\text { Parameter }\end{array}$ & .08 & - & & & & & & \\
\hline $\begin{array}{l}\text { 3. Childhood } \\
\text { Unpredictability }\end{array}$ & $-.13^{*}$ & $-.14^{*}$ & - & & & & & \\
\hline $\begin{array}{l}\text { 4. Childhood } \\
\text { Harshness }\end{array}$ & $.14^{\star}$ & .05 & $.34^{\star \star *}$ & - & & & & \\
\hline $\begin{array}{l}\text { 5. Condition } \\
\text { (control }=0 \\
\text { unpredictability }=1 \text { ) }\end{array}$ & -.09 & -.09 & .10 & .05 & - & & & \\
\hline $\begin{array}{l}\text { 6. Adult } \\
\text { Income }\end{array}$ & $-.12^{*}$ & .03 & $-.10^{\dagger}$ & $-.31^{\star \star \star}$ & $-.11^{\dagger}$ & - & & \\
\hline $\begin{array}{l}\text { 7. Gender } \\
(f=1, m=2)\end{array}$ & .01 & $-.21^{\star \star *}$ & -.03 & -.03 & .05 & -.07 & - & \\
\hline 8. Age & $.13^{*}$ & $.24^{\star \star \star}$ & $-.20^{\star *}$ & $.16^{* *}$ & -.02 & .00 & -.09 & - \\
\hline
\end{tabular}

Note: ${ }^{\dagger} p<.10,{ }^{*} p<.05,{ }^{* *} p<.01,{ }^{* * *} p<.001$ 


\section{Study 3b}

We conducted a preregistered replication of Study 3a (aspredicted.org, \#24967) with a larger sample to ensure adequate power, given smaller effect sizes than initially expected.

\section{Method.}

Participants. For an adjusted (based on Study 3a) predicted effect size $f=.17$ (between a small and medium effect) for an interaction, power analyses indicated that 483 people provided 90\% power (Faul et al., 2007). Given expected high rates of attention check failures, we decided to collect data from at least 550 people in a single wave. We collected data from six hundred and fifty-eight people via Amazon's Mechanical Turk. As preregistered, we decided a priori to exclude participants who failed (a) an attention check ( $n=187$; Oppenheimer et al., 2009), (b) to answer all dilemmas $(n=12)$, or (c) to respond appropriately to the manipulation check $(n=79)$. Our final sample included 436 individuals, which afforded about $80 \%$ power to detect small to medium interaction effects (169 females, 132 males, 1 other; $M_{\text {age }}=30.87, S D=10.77 ; 299$ White, 57 Hispanic or Latino, 53 Black, 37 Asian, 12 Native American, 2 Middle Eastern, 1 Pacific Islander, 2 multiracial, 1 'other').

Procedure and materials. Study $3 \mathrm{~b}$ was identical to Study 3a: participants watched the economic unpredictability manipulation slideshow and responded to the PD moral dilemma battery, the manipulation check/boosters, and measures of childhood unpredictability $(M=2.93$, $S D=1.70, \alpha=.93$ ), childhood harshness (items standardized and combined, $S D=.86, \alpha=.88$ ), and demographics, including adult income $(M=4.50, S D=2.11)$.

Results. First, we tested our predictions that childhood unpredictability is negatively related to both the $U$ and $D$ parameters and that current unpredictability will amplify these 
effects. Second, we examined how childhood harshness related to the parameters and explored whether any associations would vary by current unpredictability.

Childhood unpredictability. As expected, replicating Studies 1, 2, and 3a, unpredictability was negatively related to both PD parameters, such that people who experienced relatively unpredictable childhood environments less often avoided harm and maximized outcomes (see Table 3b). These associations held when controlling for childhood harshness, adult income, age, gender, and the other parameter: U parameter, $b=-.07, S E=.03, t(429)=-$ 2.36, $p=.019, \mathrm{CI}_{95}[-.128,-.012]$, and D parameter, $b=-.06, S E=.03, t(429)=-2.12, p=.035$, CI95[-.117, -.004].

Next, we tested whether childhood unpredictability interacted with current unpredictability to predict the $\mathrm{U}$ and $\mathrm{D}$ parameters. In separate regression analyses, we regressed each parameter onto childhood unpredictability (centered), condition (technology fails/control=0, current unpredictability/experimental=1), and their interaction, controlling for the other parameter. The interaction was not significant for either parameter: $\mathrm{U}$ parameter, $b=-.02, S E=$ $.06, t(431)=-0.39, p=.700, \mathrm{CI}_{95}[-.130, .087]$; D parameter, $b=.03, S E=.06, t(431)=0.60, p=$ $.550, \mathrm{CI}_{95}[-.075, .141]$. Results replicated in analyses controlling for not only the other parameter, but also childhood harshness, adult income, age, and gender: U parameter, $b=-.03$, $S E=.06, t(427)=-0.45, p=.653, \mathrm{CI}_{95}[-.133, .084]$; D parameter, $b=.02, S E=.05, t(427)=$ $0.30, p=.768, \mathrm{CI}_{95}[-.090, .121]$.

As in Study 3a, the economic unpredictability manipulation did not exert a significant main effect on either the $\mathrm{U}$ or $\mathrm{D}$ parameter: $\mathrm{U}$ parameter, $b=-.11, S E=.09, t(431)=-1.21, p=$ $.225, \mathrm{CI}_{95}[-.297, .070]$; D parameter, $b=.17, S E=.09, t(431)=1.87, p=.063, \mathrm{CI}_{95}[-.009, .357]$. These null effects held when controlling for childhood harshness, adult income, age, gender, and 
other parameter: $\mathrm{U}$ parameter, $b=-.12, S E=.09, t(427)=-1.23, p=.219, \mathrm{CI}_{95}[-.299, .069]$; D parameter, $b=.12, S E=.09, t(447)=1.29, p=.197, \mathrm{CI}_{95}[-.061, .297]$.

Childhood harshness. Harshness was marginally positively associated with utilitarian responding, consistent with Study 3a, and significantly positively associated with deontological responding. When controlling for childhood unpredictability, adult income, age, gender, and the other parameter, childhood harshness significantly positively predicted both parameters: U parameter, $b=.13, S E=.06, t(429)=2.16, p=.031, \mathrm{CI}_{95}[.012, .250]$; D parameter, $b=.18, S E=$ $.06, t(429)=3.08, p=.002, \mathrm{CI}_{95}[.066, .296]$. Thus, people who experienced relatively more resource scarcity in childhood were more likely to both reject harm and maximize overall outcomes in sacrificial dilemmas.

Next, we explored whether current economic unpredictability interacted with childhood harshness to predict moral dilemma decision making. In separate regression analyses, we regressed each parameter onto childhood harshness (standardized), condition (technology fails/control=0, current unpredictability/experimental=1), and their interaction, controlling for the other parameter. As in Study 3a, we saw evidence of a marginal trend for the interaction on the D parameter, $b=.20, S E=.11, t(431)=1.80, p=.072, \mathrm{CI}_{95}[-.018, .408]$. However, this effect did not hold controlling for childhood unpredictability, adult income, age, gender, and the other parameter, $b=.17, S E=.11, t(427)=1.61, p=.108, \mathrm{CI}_{95}[-.038, .379]$. Moreover, consistent with Study 3a, childhood harshness and current unpredictability did not interact to predict the U parameter, $b=-.11, S E=.11, t(431)=-0.97, p=.335, \mathrm{CI}_{95}[-.321, .109]$. This held when additionally controlling for childhood unpredictability, adult income, age, and gender, $b=$ $.10, S E=.11, t(427)=-.86, p=.388, \mathrm{CI}_{95}[-.310, .120] .^{7}$

\footnotetext{
${ }^{7} \mathrm{~A}$ random effects meta-analyses across Studies $3 \mathrm{a}$ and $3 \mathrm{~b}(N=579)$, correcting for differences in sample sizes (Lipsey \& Wilson, 2001; Wilson, 2010) revealed that the current unpredictability by childhood unpredictability
} 
Discussion. Study 3b replicated the key pattern in Studies 1, 2, and 3a: people who experienced more unpredictable childhood environments were less likely to both reject harm and maximize outcomes in sacrificial dilemmas. Conversely, childhood harshness was positively associated with utilitarian and deontological response tendencies. That is, people who experienced harsher childhood environments tended to both reject harm and maximize outcomes more often. Contrary to predictions, the current economic unpredictability manipulation failed to amplify the relationship between childhood unpredictability and moral response tendencies (see Footnote 6), nor did the unpredictability manipulation interact with harshness or directly impact dilemma responses. By replicating these null effects across two preregistered studies, we are fairly confident in concluding that current environmental unpredictability did not impact dilemma judgments, suggesting that perhaps the processes underlying moral dilemma responses are largely insensitive to immediate conditions of environmental unpredictability.

Consistent with that idea, response plasticity to present environmental cues should be selective because there are inherent costs to such shifts (see DeWitt et al., 1998, for a review). First, flexibility requires metabolic energy allotted to collecting data from the environment. Second, data collected from the environment could be inconsistent with broader ecological conditions, and therefore misleading, such that adjusting to an environment in which one does not actually reside would be disadvantageous. Because a complex confluence of socioemotional individual differences calibrated in early childhood contributes to moral dilemma decisions, one minute's worth of information about the current environment may not be sufficient to shift

interaction was not significant for the $\mathrm{U}$ parameter, $b=-.03, Z=-.71, p=.478, \mathrm{CI}_{95}[-.113, .053]$, which did not vary in magnitude across studies, $Q(1)=.06, p=.814$, or the $\mathrm{D}$ parameter, $b=-.05, Z=-.70, p=.485, \mathrm{CI}_{95}[-.172, .082]$, which did not vary in magnitude across studies. Likewise, there was no metanalytic main effect of current unpredictability on the $\mathrm{U}$ parameter, $b=-.06, Z=-1.54, p=.123, \mathrm{CI}_{95}[-.148, .018]$, which did not vary in magnitude across studies, $Q(1)=.35, p=.554$, or the $\mathrm{D}$ parameter, $b=-.005, Z=-.06, p=.950, \mathrm{CI}_{95}[-.171, .160]$, which varied in magnitude across studies, $Q(1)=4.03, p=.045$. 
people's tendencies to avoid harm and maximize outcomes. In the next study, we examined whether individual differences related to trusting, empathizing with, and supporting others account for the consistent finding that childhood unpredictability is associated with less harm avoidance and outcome maximization. 
Table $3 b$

Correlations Among Variables, Study $3 b$.

\begin{tabular}{|c|c|c|c|c|c|c|c|c|}
\hline & 1 & 2 & 3 & 4 & 5 & 6 & 7 & 8 \\
\hline $\begin{array}{l}\text { 1. Utilitarian PD } \\
\text { Parameter }\end{array}$ & - & & & & & & & \\
\hline $\begin{array}{l}\text { 2. Deontology PD } \\
\text { Parameter }\end{array}$ & $.22^{* * *}$ & - & & & & & & \\
\hline $\begin{array}{l}\text { 3. Childhood } \\
\text { Unpredictability }\end{array}$ & $-.12^{*}$ & $-.12^{*}$ & - & & & & & \\
\hline $\begin{array}{l}\text { 4. Childhood } \\
\text { Harshness }\end{array}$ & $.08^{\dagger}$ & $.13^{\star *}$ & $.30^{* * *}$ & - & & & & \\
\hline $\begin{array}{l}\text { 5. Condition } \\
\text { (control=0, } \\
\text { unpredictability=1) }\end{array}$ & -.04 & .08 & .01 & .04 & - & & & \\
\hline $\begin{array}{l}\text { 6. Adult } \\
\text { Income }\end{array}$ & $.09^{\dagger}$ & .08 & $-.14^{\star \star}$ & $-.28^{\star \star \star}$ & -.03 & - & & \\
\hline $\begin{array}{l}\text { 7. Gender } \\
(f=1, m=2)\end{array}$ & -.02 & $-.19^{\star * *}$ & .07 & .00 & $-.10^{*}$ & .01 & - & \\
\hline 8. Age & $.11^{*}$ & $.17^{* * *}$ & $-.14^{\star *}$ & $.14^{* *}$ & .08 & .05 & $-.13^{\star \star}$ & - \\
\hline
\end{tabular}

Note: ${ }^{\dagger} p<.10,{ }^{*} p<.05,{ }^{* *} p<.01,{ }^{* * *} p<.001$ 


\section{Study 4}

Study 4 (preregistered, aspredicted.org, \#27262) tested whether other-oriented individual differences would account for the relationships between childhood unpredictability and weaker tendencies to avoid harm and maximize outcomes on sacrificial moral dilemmas. Unpredictable childhood environments are associated with social functioning optimized for garnering resources for the self at the cost of others - such as reduced empathy, a general distrust of others, belief that the world is dangerous, and poorer quality relationships with close others (e.g., Jonason et al., 2016, 2017; Zhu et al., 2018, 2019). Hence, we expected that empathic concern, trust, and relationship network quality would be negatively associated with childhood unpredictability, whereas belief in a dangerous world would be positively associated with childhood unpredictability.

Furthermore, concern for individuals and the group predict deontological and utilitarian response tendencies (e.g., Conway \& Gawronski, 2013; Conway et al., 2018; Reynolds \& Conway, 2018), such that we expected trust in others and relationship quality to be positively associated and belief in a dangerous world to be negatively associated with both parameters. Empathic concern more often predicts deontological than utilitarian response tendencies (e.g., Conway \& Gawronski, 2013; Conway et al., 2018; Reynolds \& Conway, 2018), and we expected a similar pattern of associations here. Accordingly, we expected reduced empathic concern, a general distrust of others, belief that the world is dangerous, and poorer quality relationships with close others to at least partially mediate the relationships between childhood unpredictability and lower deontological and utilitarian concerns. We also explored whether these variables accounted for any associations between childhood harshness and dilemma responses and whether mediation results hold above and beyond personality variables. 
Participants. To detect the hypothesized indirect effects (with predicted effect sizes of .26 for each path in the mediational chain, based on the previous studies), an a priori power analysis indicated that we needed 162 people to reach 80\% power (Fritz \& MacKinnon, 2007). To increase power, particularly given the potential for high levels of data exclusion due to inattentive responding, we collected data from 321 participants via Amazon’s Mechanical Turk. As preregistered, we decided a priori to exclude participants who failed an attention check $(n=$ 69; Oppenheimer et al., 2009) or failed to answer all dilemmas $(n=20)$. Our final sample included 250 individuals (121 females, 128 males; $M_{\text {age }}=34.61, S D=10.16 ; 171$ White, 41 Black, 26 Hispanic or Latino, 6 Asian, 4 Native American, 3 Pacific Islander, 1 'mixed').

Procedure and materials. As before, participants responded to the moral dilemma battery, measures of childhood unpredictability $(M=3.31, S D=1.76, \alpha=.95)$, childhood harshness (items standardized and combined, $S D=.83, \alpha=.85$ ), and demographics, including adult income $(M=4.40, S D=1.74)$. New to this study, participants also completed measures of empathic concern, general trust, belief in a dangerous world, social support quality, and the Big 5 personality traits.

Empathic concern. Participants responded to seven items (Davis, 1983), such as When I see someone being taken advantage of, I feel kind of protective toward them and Sometimes I don't feel sorry for other people when they are having problems (reversed), on scales from 1 (does not describe me well) to 5 (describes me very well). We averaged scores across items, such that higher scores represent more empathic concern $(M=3.70, S D=.78, \alpha=.80)$.

General trust. Participants responded to the six items of the General Trust Scale (Yamagishi \& Yamagishi, 1994), such as People are basically honest and People are trustworthy, on a scale from 1 (strongly disagree) to 7 (strongly agree). We averaged scores 
across items, such that higher scores represent more trusting in general $(M=4.82, S D=1.20, \alpha=$ $.92)$.

Belief in a dangerous world. Participants responded to 12 items of the Belief in a Dangerous World scale (Altemeyer, 1988), which includes items such as There are many dangerous people in our society who will attack someone out of pure meanness, for no reason at all and If a person takes a few sensible precautions, nothing bad will happen to him. We do not live in a dangerous world (reversed) on scale from 1 (strongly disagree) to 7 (strongly agree). We averaged scores across items, such that higher scores represent stronger beliefs that the world is dangerous $(M=4.06, S D=.99, \alpha=.84)$.

Close relationship support quality. Participants responded to 15 items of an adapted short form of the Network of Relationships Questionnaire (Furman \& Buhrmester, 1985) to measure social support provisions in "relationships with family, parents, friends, and your romantic partner-close others" on scale from 1 (strongly disagree) to 7 (strongly agree). Sample items include These people help me figure out or fix things and We often argue with each other (reversed). We averaged scores across items, such that higher scores represent better relationship quality $(M=4.65, S D=.88, \alpha=.85)$.

Personality. To control for personality in the mediation analyses, participants responded to the Ten-Item Personality Inventory (Gosling et al., 2003). We included each of the Big Five traits as control measures in secondary analyses: openness to experience $(M=4.93, S D=1.25, \alpha$ $=.33)$, conscientiousness $(M=5.16, S D=1.27, \alpha=.45)$, extraversion $(M=3.77, S D=1.50, \alpha=$ $.59)$, agreeableness $(M=5.05, S D=1.21, \alpha=.33)$, and neuroticism $(M=3.40, S D=1.38, \alpha=$ $.56)$.

\section{Results}


We tested whether childhood unpredictability was negatively and harshness was positively (or not related) to deontological and utilitarian dilemma responding. We also examined how empathic concern, general trust, belief in a dangerous world, and relationship support quality were related to the $\mathrm{D}$ and $\mathrm{U}$ parameters and to childhood unpredictability and harshness. Finally, we examined whether these individual differences in social functioning mediated the associations between childhood ecological factors and moral dilemma response tendencies.

Childhood unpredictability. Consistent with predictions and replicating the previous studies, childhood unpredictability was negatively related to both PD parameters (see Table 4). People who experienced relatively more unpredictability in early childhood demonstrated less harm aversion and outcome maximization. These associations held when controlling for childhood harshness, adult income, age, gender, and the other parameter: D parameter, $b=-.16$, $S E=.03, t(242)=-4.77, p<.001, \mathrm{CI}_{95}[-.222,-.092]$, and $\mathrm{U}$ parameter, $b=-.10, S E=.04, t(242)$ $=-2.84, p=.005, \mathrm{CI}_{95}[-.169,-.031]$.

Childhood harshness. Consistent with Study 3b, early ecological harshness was positively associated with both the $\mathrm{D}$ and $\mathrm{U}$ parameters. People with access to fewer versus more resources during childhood more often rejected harm and maximized overall wellbeing. When controlling for childhood unpredictability, adult income, age, gender, and the other parameter, the association between harshness and the $\mathrm{D}$ parameter dropped to a marginal trend, $b=.12, S E$ $=.07, t(242)=1.75, p=.082, \mathrm{CI}_{95}[-.016, .265]$, but the association between harshness and the $\mathrm{U}$ parameter remained significant, $b=.17, S E=.07, t(242)=2.24, p=.026, \mathrm{CI}_{95}[.020, .309]$.

Individual differences in social functioning. Next, we assessed whether the individual difference measures were associated with the PD parameters. Empathic concern was 
significantly positively associated with the D parameter as expected, but also positively associated with the U parameter, contrary to predictions but consistent with some work (e.g., Maranges et al., 2020a, 2020b). Unexpectedly, general trust in others was negatively associated with both parameters and belief in a dangerous world was unrelated to either parameter. As predicted, relationship support quality was significantly positively related to both parameters. To summarize, higher levels of empathic concern and relationship support quality, and lower levels of trust, were associated with a tendency to reject harm and a tendency to favor actions that increase the overall wellbeing of others.

We then assessed whether the individual difference measures were associated with childhood unpredictability and harshness. Empathic concern and relationship support quality, but not the other individual differences, were significantly negatively associated with childhood unpredictability. This suggests people who experienced more unpredictable childhood environments were less concerned about the wellbeing of others and experienced less supportive close relationships. General trust in others, but no other individual difference, was significantly negatively associated with childhood harshness: the more resource scarce people's childhood environments, the less they trust other people generally.

Mediation analyses. As preregistered, we tested whether the candidate mediators (i.e., empathic concern, general trust, belief in a dangerous world, and relationship support quality) accounted for significant indirect variance in the relationships between childhood unpredictability and the moral dilemma parameters. We conducted two separate 10,000 bootstrapping resample mediation analyses using Model 4 in the PROCESS Macro for SPSS (Preacher \& Hayes, 2004)—one for the utilitarian parameter and one for the deontology parameter. In each analysis, putative mediators were tested simultaneously to account for their 
shared variance. We also conducted parallel analyses to explore potential mediation of the links between childhood harshness and the parameters. Finally, we reran each analysis including control variables.

Childhood unpredictability. Regarding utilitarian response tendencies, less empathic concern, $b=-.03, S E=.01, \mathrm{CI}_{95}[-.065,-.017]$, and less close relationship support quality, $b=-$ $.04, S E=.01, \mathrm{CI}_{95}[-.070,-.014]$, mediated the relationship between childhood unpredictability and the U parameter (see Figure 1). Neither trust in others, $b=-.02, S E=.01, \mathrm{CI}_{95}[-.040, .003]$, nor belief in a dangerous world, $b=.00, S E=.01, \mathrm{CI}_{95}[-.010,-.016]$, mediated this link (see Figure 1). Controlling for childhood harshness, adult income, age, gender, the big five personality traits, and the other parameter: the effect of unpredictability on utilitarian responding through empathic concern became marginal, $b=-.01, S E=.01, \mathrm{CI}_{95}[-.024, .002]$; through relationship support quality remained significant, $b=-.01, S E=.01, \mathrm{CI}_{95}[-.040,-.002]$; through trust became significant, $b=-.02, S E=.01, \mathrm{CI}_{95}[-.040,-.001]$; through belief in a dangerous world remained nonsignificant, $b=-.00, S E=.01, \mathrm{CI}_{95}[-.014, .008]$.

Similar mediation effects emerged for deontological response tendencies. As predicted, less empathic concern, $b=-.04, S E=.01, \mathrm{CI}_{95}[-.065,-.017]$, and less close relationship support quality, $b=-.03, S E=.01$, CI95[-.054, -.004], mediated the relationship between childhood unpredictability and the D parameter (see Figure 2). Neither trust in others, $b=-.01, S E=.01$, $\mathrm{CI}_{95}[-.032, .001]$, nor belief in a dangerous world, $b=.00, S E=.00, \mathrm{CI}_{95}[-.001, .012]$, mediated this link. Controlling for childhood harshness, adult income, age, gender, the big five personality traits, and the other parameter: the effect of unpredictability on deontological responding through empathic concern became marginal, $b=-.01, S E=.01, \mathrm{CI}_{95}[-.023, .002]$; through relationship support quality became nonsignificant, $b=-.00, S E=.01, \mathrm{CI}_{95}[-.017, .011]$; through trust 
remained nonsignificant, $b=-.00, S E=.01, \mathrm{CI}_{95}[-.025, .011]$; through belief in a dangerous world remained nonsignificant, $b=-.00, S E=.00, \mathrm{CI}_{95}[-.012, .005]$. Thus, people who experienced relatively unpredictable childhood environments experienced less empathic concern, less supportive close relationships, and (to a degree) less trust in others, which partially accounted for less concern about rejecting harm to and maximizing outcomes for others.

Childhood harshness. Childhood harshness was associated with higher levels of utilitarian responding through less trust in others, $b=.11, S E=.03$, $\mathrm{CI}_{95}[.056, .185]$, but not through empathic concern, $b=.03, S E=.02, \mathrm{CI}_{95}[-.003, .082]$, relationship support quality, $b=$ $.02, S E=.02, \mathrm{CI}_{95}[-.017, .062]$, or belief in a dangerous world, $b=-.01, S E=.02, \mathrm{CI}_{95}[-.050$, .015]. This pattern held when controlling for childhood unpredictability, adult income, age, gender, the big five personality traits, and the other parameter: there remained a significant indirect effect via trust in others, $b=.05, S E=.03, \mathrm{CI}_{95}[.003, .115]$, but not via empathic concern, $b=.00, S E=.01, \mathrm{CI}_{95}[-.012, .026]$; relationship support quality, $b=.00, S E=.01$, $\mathrm{CI}_{95}[-.016, .035]$; or belief in a dangerous world, $b=.00, S E=.01, \mathrm{CI}_{95}[-.019, .029]$.

A similar pattern emerged for the deontological parameter, such that childhood harshness predicted harm aversion on moral dilemmas through less trust in others, $b=.08, S E=.03$, $\mathrm{CI}_{95}[.030, .151]$, but not through empathic concern, $b=.04, \mathrm{SE}=.02$, $\mathrm{CI}_{95}[-.004, .090]$; relationship support quality, $b=.02, S E=.02, \mathrm{CI}_{95}[-.017, .055]$; or belief in a dangerous world, $b$ $=-.01, S E=.01, \mathrm{CI}_{95}[-.039, .008]$. This held when controlling for childhood unpredictability, adult income, age, gender, the big five personality traits, and the other parameter: trust in others, $b=.01, S E=.03, \mathrm{CI}_{95}[-.041, .069]$, but not through empathic concern, $b=.00, S E=.01, \mathrm{CI}_{95}[-$ $.011, .026]$; relationship support quality, $b=.00, S E=.01, \mathrm{CI}_{95}[-.009, .017]$; or belief in a dangerous world, $b=.00, S E=.01, \mathrm{CI}_{95}[-.015, .017]$. In sum, people who experienced higher 
levels of childhood harshness experienced less trust in others, which was associated with less harm aversion and less outcome maximization across moral dilemmas. Notably, however, harshness was associated with higher (not lower) levels of harm aversion and outcome maximization, thus rendering the results of this mediation analysis difficult to interpret.

\section{Discussion}

Replicating Studies 1, 2, 3a, and 3b, we found that people who experienced more unpredictable childhood environments made fewer deontological and utilitarian moral dilemma decisions. Furthermore, mediation analyses suggested that empathic concern and relationship support quality partially accounted for these relationships: people with relatively unpredictable childhoods experienced lower empathic concern and lower quality close relationships, which in turn predicted weaker tendencies to avoid harm and maximize outcomes on moral dilemmas. In contrast, childhood harshness was associated with increased deontological and utilitarian responding across moral dilemmas, consistent with Study 3 and the idea that resource scarcity encourages concern for others. This work adds to a growing body of literature underscoring the importance of dissociating the early ecological factors of unpredictability and harshness, which contribute to complex moral decision making in different ways. Nonetheless, it may be important to consider a wider range of features characterizing childhood ecologies than examined so farthe goal of Study 5 . 
Table 4

Correlations Among Variables, Study 4.

\begin{tabular}{|c|c|c|c|c|c|c|c|c|c|c|}
\hline & 1 & 2 & 3 & 4 & 5 & 6 & 7 & 8 & 9 & 10 \\
\hline $\begin{array}{l}\text { 1. Utilitarian PD } \\
\text { Parameter }\end{array}$ & - & & & & & & & & & \\
\hline $\begin{array}{l}\text { 2. Deontology PD } \\
\text { Parameter }\end{array}$ & $.39^{* * *}$ & - & & & & & & & & \\
\hline $\begin{array}{l}\text { 3. Childhood } \\
\text { Unpredictability }\end{array}$ & $-.29^{\star \star \star *}$ & $-.36^{* * *}$ & - & & & & & & & \\
\hline $\begin{array}{l}\text { 4. Childhood } \\
\text { Harshness }\end{array}$ & $.21^{* *}$ & $.20^{\star *}$ & -.02 & - & & & & & & \\
\hline $\begin{array}{l}\text { 5. Empathic } \\
\text { Concern }\end{array}$ & $.24^{\star \star \star *}$ & $.29^{* * *}$ & $-.28^{\star \star \star}$ & .11 & - & & & & & \\
\hline $\begin{array}{l}\text { 6. General } \\
\text { Trust }\end{array}$ & $-.20^{\star \star \star}$ & $-.14^{* \star}$ & .10 & $-.32^{* \star *}$ & $.17^{\star \star}$ & - & & & & \\
\hline $\begin{array}{l}\text { 7. Belief in a } \\
\text { Dangerous World }\end{array}$ & -.08 & -.03 & -.01 & .05 & .09 & $-.24^{* * *}$ & - & & & \\
\hline $\begin{array}{l}\text { 8. Relationship } \\
\text { Support Quality }\end{array}$ & $.25^{* \star *}$ & $.25^{* * *}$ & $-.41^{\star \star * *}$ & .07 & $.31^{* \star *}$ & $.15^{*}$ & -.01 & - & & \\
\hline $\begin{array}{l}\text { 9. Adult } \\
\text { Income }\end{array}$ & .03 & .01 & .06 & $-.22^{* * *}$ & .01 & $.17^{* *}$ & $-.22^{\star \star \star}$ & $.16^{\star}$ & - & \\
\hline $\begin{array}{l}\text { 10. Gender } \\
(f=1, m=2)\end{array}$ & $-.25^{\star \star \star}$ & $-.29^{* * *}$ & .07 & $-.21^{* *}$ & $-.34^{\star \star \star}$ & .03 & $-.12^{\dagger}$ & $-.21^{\star *}$ & .03 & - \\
\hline 11. Age & $.11^{\dagger}$ & $.15^{\star}$ & $-.18^{\star \star}$ & $.21^{* *}$ & $.12^{\dagger}$ & .08 & .05 & $.19^{* *}$ & -.04 & $-.14^{\star}$ \\
\hline
\end{tabular}




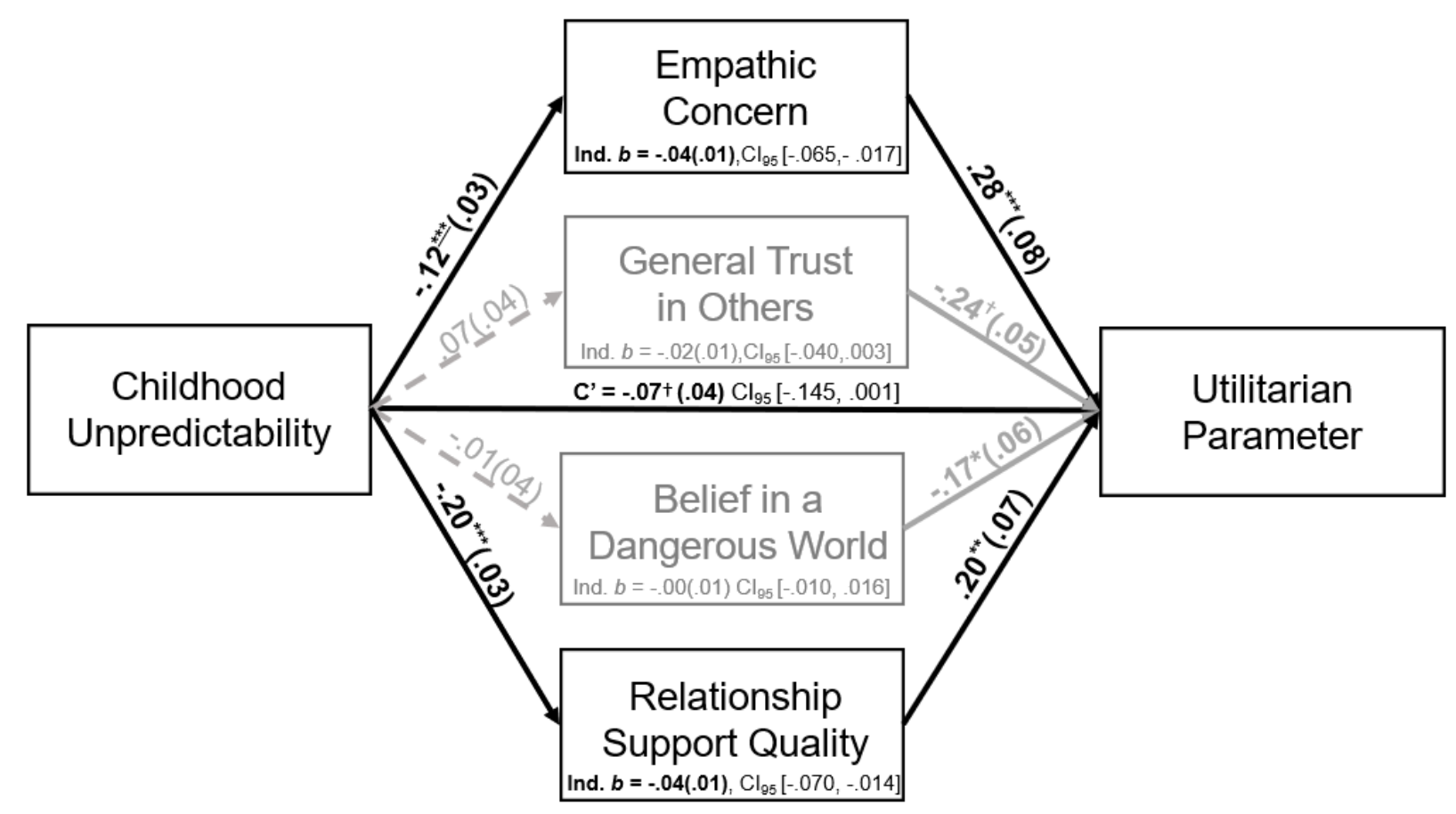

Figure 1.

Childhood unpredictability is associated with lower utilitarian response tendencies through lower empathic concern and close relationship support quality, but not through general trust in others or belief in a dangerous world, Study 4. Solid lines indicate significant effects, dotted lines indicate non-significant effects; significant mediation pathways in black, non-significant pathways depicted in grey. Note: ${ }^{\dagger} p<.10,{ }^{*} p<.05,{ }^{* *} p<.01,{ }^{* * *} p<.001$ 


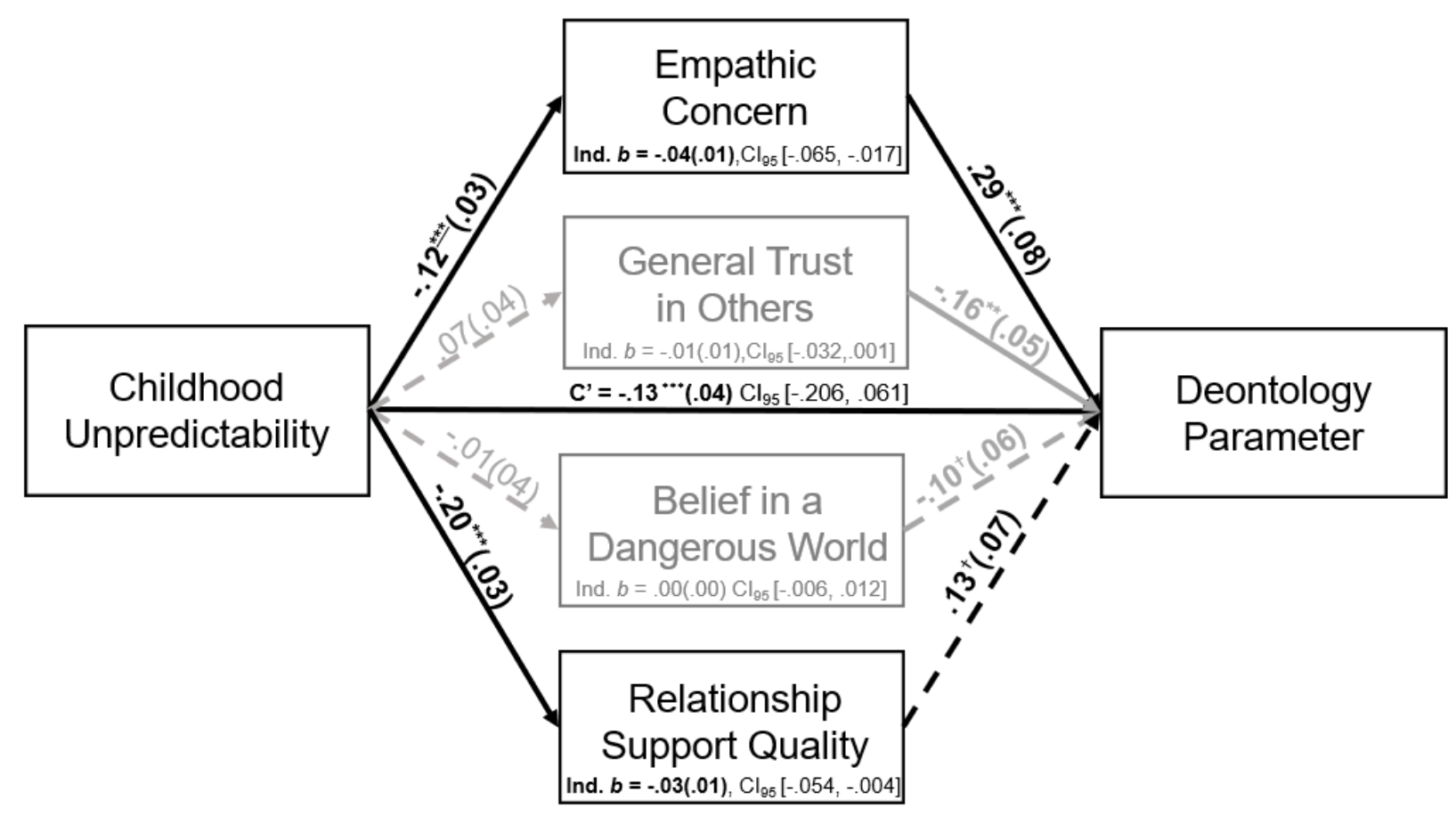

Figure 2.

Childhood unpredictability is associated with lower deontological response tendencies through lower empathic concern and close relationship support quality, but not through general trust in others or belief in a dangerous world, Study 4. Solid lines indicate significant effects, dotted lines indicate non-significant effects; significant mediation pathways in black, non-significant pathways depicted in grey. Note: ${ }^{\dagger} p<.10,{ }^{*} p<.05,{ }^{* *} p<.01,{ }^{* * *} p<.001$ 


\section{Study 5}

Studies 1-4 established that childhood unpredictability (but not harshness) is associated with reduced harm rejection and outcome maximization on sacrificial dilemmas, but those studies were somewhat limited by a reliance on measures that may fall short of fully tapping the constructs of unpredictability and harshness. Therefore, in Study 5 we created and used new measures to assess unpredictability and harshness. The unpredictability measure not only included a more comprehensive set of items, but also differentiated between sources of unpredictability involving social (e.g., neighbors, teachers, peers) and nonsocial or physical (e.g., weather, neighborhood structure, financial) features of the environment. The harshness measure also included a more comprehensive set of items tapping a number of different sources of ecological harshness (e.g., lack of food, clothing, electricity) that go beyond family income. This allowed for a stronger test of whether childhood harshness plays a role in adult moral dilemma decision making.

We expected negative associations between childhood social unpredictability and both harm-rejection (deontological) and outcome-maximizing (utilitarian) moral dilemma responses. We expected a similar pattern for childhood physical unpredictability. Additionally, we expected childhood harshness to be either positively or not significantly associated with deontological and utilitarian response patterns. In addition, Study 5 aimed to elucidate the role of potential confounds, namely, religiosity, political orientation, Big 5 personality $\operatorname{traits}^{8}$, and social desirability in the association between childhood ecological factors and moral decision making. Specifically, we address whether the associations between childhood unpredictability and

\footnotetext{
${ }^{8}$ We used a longer and psychometrically stronger measure than in Study 4 (Lang et al., 2011; Hahn et al., 2012).
} 
utilitarian and deontological responses (a) hold above and beyond or (b) are mediated by these individual differences.

Participants. We decided a priori to collect data from at least 500 people via Amazon's Mechanical Turk in a single wave. This is based on (a) Fritz \& MacKinnon's (2007) analysis for a small effect size for $\mathrm{X} \rightarrow \mathrm{M}$ and $\mathrm{M} \rightarrow \mathrm{X}$, which indicated that 412 people will be needed to reach $80 \%$ power, (b) our having found small-to-medium effects in a prior mediation study, (c) an aim to increase our power from $80 \%$, and (d) due to expected exclusions based on prior studies. We collected data from 501 people. As preregistered, we excluded participants who failed one or more of two attention checks ( $n=268$; Oppenheimer et al., 2009) or failed to answer all dilemmas ( $n=10,3$ of whom also failed attention check). Our final sample included 220 individuals (117 females, 99 males, 1 other; $M_{\text {age }}=31.71, S D=10.68 ; 151$ White, 31 Hispanic or Latino, 18 Black, 7 Asian, 7 Native American, 4 Pacific Islander, 1 Bengali, 1 Middle Eastern). The reduced sample afforded above $80 \%$ power to detect small-to-medium effects in exploratory mediation analyses (Fritz \& MacKinnon, 2007) and above 90\% power to detect small-to-medium effects in our primary correlation and regression analyses (Faul et al., 2007).

Procedure and materials. As before, participants responded to the PD moral dilemma battery, measures of childhood unpredictability and harshness, and demographics, including adult income $(M=4.50, S D=1.83)$. We included new, extended measures of childhood social and physical unpredictability, as well as of childhood harshness (see Supplemental materials for items and their development). Participants also responded to measures of religiosity, political orientation, personality, and social desirability. 
Childhood social unpredictability. Participants responded to 24 items, including the original eight (Mittal et al., 2015; Young et al., 2018), capturing the extent to which their childhood environments were characterized by unpredictability on a 1 (strongly disagree) to 7 (strongly agree) scale. Sample new items include My parents went through multiple separations or divorces, My family often moved homes and schools when I was a child, and I often did not know what to expect from other students at school. We averaged scores across items, and higher scores represent more unpredictable social environments $(M=3.38, S D=1.38, \alpha=.95)$.

Childhood physical unpredictability. Participants reported the unpredictability of their physical childhood environments by responding to 12 items on a 1 (strongly disagree) to 7 (strongly agree) scale. Sample items include I was never certain where it was safe to play, There was a lot of change in the structure (e.g., buildings, signs) of my neighborhood, and I experienced extreme, unexpected weather events when I was a kid (e.g., volcano erupting, earthquake, tsunami). We averaged scores across items, and higher scores represent more unpredictable physical environments $(M=3.18, S D=1.65, \alpha=.95)$.

Childhood harshness. Participants responded to 28 items total: 27 items, including the original three (Mittal et al., 2015; Young et al., 2018), captured the extent to which their childhood environments were characterized by scarcity (vs. abundance) of resources on a 1 (strongly disagree) to 7 (strongly agree; $M=3.75, S D=1.18$ ) scale. As in the prior studies and original measure, one item asked about income on an 8-point scale $(M=4.65, S D=1.71)$. Sample new items include My family was strained financially, Sometimes we lost access to heating, water, or electricity because of overdue bills, and My caregivers typically got me any food I wanted from the grocery store (reversed). For the final composite, which includes items 
on different scales, we standardized and averaged across items, and higher scores represent harsher childhood environments $(S D=.61, \alpha=.94)$.

Religiosity. Participants responded to the ten-item Santa Clara Strength of Religious Faith Questionnaire (Plante \& Boccaccini, 1997) on a scale from 1 (strongly disagree) to 7 (strongly agree). Sample items include My religious faith is extremely important to me and My faith impacts many of my decisions. We averaged scores across items, and higher scores represent more religiosity $(M=4.34, S D=1.93, \alpha=.98)$.

Political orientation. Participants responded to the question How would you describe your political orientation? on a 1 (extremely liberal) to 7 (extremely conservative) scale with additional options I haven't thought much about this $(n=6)$ and Libertarian/none of these $(n=$ 11). Removing the latter two options, higher scores represent relatively more conservative political orientations $(M=4.59, S D=2.30)$. Hence, in analyses, we refer to this construct as political conservativism.

Personality. Participants responded to the 15-item Big Five Inventory (Lang et al., 2011; Hahn et al., 2012). Participants rated their agreement with "I see myself as someone who..." statements on 1 (strongly disagree) to 7 (strongly agree) scale. We averaged across three items to calculate each trait: openness to experience (e.g., is original, comes up with new ideas; $M=$ $5.46, S D=.94, \alpha=.64$ ), conscientiousness (e.g., does a thorough job; $M=5.14, S D=.95, \alpha=$ .43), extraversion (e.g., is outgoing, sociable; $M=4.14, S D=1.08, \alpha=.52$ ), agreeableness (e.g., has a forgiving nature; $M=5.08, S D=.94, \alpha=.36$ ), and neuroticism (e.g., worries a lot; $M=$ $4.09, S D=1.24, \alpha=.62)$.

Social desirability. Participants responded to the Marlowe-Crowne Social Desirability Scale short form, containing 13 True-False items that capture the tendency to self-report in 
positively biased ways, at the cost of honesty (Reynolds, 1982). Sample items include No matter who I'm talking to, I'm always a good listener and There have been occasions when I took advantage of someone (reversed). We summed positively biased responses to create a social desirability score for each participant $(M=6.25, S D=2.88, \alpha=.69)$.

\section{Results}

We tested whether childhood unpredictability predicted less harm aversion (D parameter) and outcome maximizing (U parameter). To examine whether social, physical, or both types of childhood unpredictability contribute to moral dilemma decisions in adulthood, we examined them separately. Nonetheless, it is important to note that childhood social and physical unpredictability were highly correlated, suggesting that people who experienced highly unpredictable social environments also experienced highly unpredictable physical environments (see Table 5). We also tested whether childhood harshness was related to the parameters. As in prior studies, harshness was moderately associated with social unpredictability, and new to this study, with physical unpredictability. Also new to this study, we examined whether the associations between childhood unpredictability and harshness and moral dilemma response tendencies held above and beyond potential confounds (religiosity, political orientation, Big 5 personality traits, and social desirability). Finally, we explored whether these potential confounds may fall in the causal chain linking childhood unpredictability and harshness and moral dilemma response tendencies via mediation analyses.

Regression analyses. As preregistered, we tested whether the associations among childhood social and physical unpredictability and harshness and the PD parameters hold not only controlling for demographic variables as in past studies but also potential confoundsreligiosity, political orientation, personality, and social desirability. As preregistered, we 
examined zero-order correlations in a first step and included in subsequent regression analyses only those predictors demonstrating significant or marginal associations with the parameters $(p<$ .10). Religiosity and political conservativism were negatively associated with the U parameter, whereas conscientiousness was positively associated. Conservativism, extroversion, and neuroticism were negatively associated with the D parameter, whereas conscientiousness, agreeableness, and social desirability were positively associated. People who experienced relatively more unpredictable social and physical environments in childhood also reported higher levels of religiosity, conservativism, extroversion, and neuroticism, as well as lower levels of conscientiousness and agreeableness. People who experienced harsher childhood environments also reported higher neuroticism.

Childhood social unpredictability. Consistent with predictions, and replicating the previous studies, childhood social unpredictability was negatively related to both PD parameters, such that people who experienced relatively more unpredictability were less likely to reject harm and maximize outcomes (see Table 5). These associations held when controlling for childhood harshness, adult income, age, gender, and the other parameter: $\mathrm{D}$ parameter, $b=-.38, S E=.06$, $t(210)=-6.41, p<.001, \mathrm{CI}_{95}[-.495,-.262], \mathrm{U}$ parameter, $b=-.36, S E=.06, t(242)=-5.92, p<$ $.001, \mathrm{CI}_{95}[-.480,-.240]$.

Likewise, when controlling for political conservativism, extroversion, neuroticism, conscientiousness, agreeableness, social desirability and the other parameter, childhood social unpredictability continued to negatively predict the D parameter, $b=-.18, S E=.05, t(191)=-$ $3.50, p<.001, \mathrm{CI}_{95}[-.284,-.079]$. When controlling for religiosity, political conservativism, and conscientiousness, and the other parameter, childhood social unpredictability still negatively predicted the U parameter, $b=-.14, S E=.06, t(194)=-2.51, p=.013, \mathrm{CI}_{95}[-.247,-.030]$. 
Childhood physical unpredictability. Consistent with predictions, childhood physical unpredictability was negatively related to both PD parameters, such that people who experienced relatively more unpredictability in their physical environment were less likely to reject harm and maximize outcomes (see Table 5). These associations held when controlling for childhood harshness, adult family income, age, gender, and the other parameter: D parameter, $b=-.34, S E$ $=.05, t(210)=-7.24, p<.001, \mathrm{CI}_{95}[-.431,-.247]$, and $\mathrm{U}$ parameter, $b=-.36, S E=.05, t(210)=-$ $7.83, p<.001, \mathrm{CI}_{95}[-.446,-.266] .^{9}$

When controlling for political conservativism, extroversion, neuroticism, conscientiousness, agreeableness, social desirability and the other parameter, childhood physical unpredictability continued to negatively predict the D parameter, $b=-.21, S E=.05, t(191)=-$ $4.58, p<.001, \mathrm{CI}_{95}[-.297,-.118]$. When controlling for religiosity, political conservativism, and conscientiousness, and the other parameter, childhood physical unpredictability still negatively predicted the U parameter, $b=-.21, S E=.05, t(194)=-4.27, p<.001, \mathrm{CI}_{95}[-.303,-.112]$.

Childhood harshness. Replicating Studies 1 and 2, but not Studies 3 and 4, ecological harshness in childhood was not associated with either the D or the U parameter. However, when controlling for childhood social and physical unpredictability, adult income, age, gender, and the other parameter, harshness became a significant predictor of higher levels of both dilemma response tendencies: D parameter, $b=.37, S E=.13, t(209)=2.87, p=.005, \mathrm{CI}_{95}[.115, .622], \mathrm{U}$ parameter, $b=.43, S E=.13, t(209)=3.35, p=.001, \mathrm{CI}_{95}[.175, .676]$. Thus, consistent with Studies 3 and 4, the fewer resources people had when growing up, the more they rejected harm and maximized outcomes.

\footnotetext{
${ }^{9}$ Given the high correlation and multicollinearity between childhood social and physical unpredictability and subsequent interpretability issues, we relegate analyses that include both as predictors to the supplemental materials.
} 
When controlling for political conservativism, extroversion, neuroticism, conscientiousness, agreeableness, social desirability, and the other parameter, however, childhood harshness no longer significantly predicted the D parameter, $b=-.05, S E=.11, t(191)$ $=-0.45, p=.653, \mathrm{CI} 95[-.265, .166]$. However, when controlling for religiosity, political conservativism, and conscientiousness, and the other parameter, childhood harshness was no longer associated with the $\mathrm{U}$ parameter, $b=-.01, S E=.11, t(194)=-.10, p=.920, \mathrm{CI}_{95}[-.228$, .206].

Mediation analyses. As preregistered, we tested whether the candidate mediators (religiosity, political conservativism, Big 5 personality traits, and social desirability) accounted for significant indirect variance in the relationships between childhood environments and the PD parameters. In a first step, we tested whether each mediator separately carried significant indirect variance between social unpredictability, physical unpredictability, and harshness, and each PD parameter in separate 10,000 bootstrapping resample mediation analyses using Model 4 in the PROCESS Macro for SPSS (Preacher \& Hayes, 2004). ${ }^{10}$ In a second step, we included significant mediators from step one in a simultaneous mediation model to account for their shared variance.

Childhood social unpredictability. In the first step, only agreeableness accounted for significant indirect variance between childhood social unpredictability and the $\mathrm{D}$ parameter, $b=$ $.04, S E=.01, \mathrm{CI}_{95}[-.078,-.021]$, an effect that remained significant when entering the other Big 5 personality traits simultaneously, $b=-.04, S E=.01, \mathrm{CI}_{95}[-.073,-.013]$. People who experienced

\footnotetext{
${ }^{10}$ For personality traits, we tested them both individually and simultaneously (i.e., entered all five personality traits - openness to experience, conscientiousness, extroversion, agreeableness, neuroticism - into the model at once).
} 
more unpredictable social environments as children were less agreeable, and this contributed to less concern about rejecting harm.

Religiosity and political conservativism each individually accounted for significant indirect variance between childhood social unpredictability and the U parameter. Together in the same model, religiosity, $b=-.05, S E=.02$, CI95[-.092, -.025], but not conservativism, $b=-.01$, $S E=.02, \mathrm{CI}_{95}[-.056, .023]$, mediated the relationship between childhood social unpredictability and utilitarian response tendencies. That is, controlling for conservativism, people who experienced more unpredictable social environments as children were more religious, and this contributed to less outcome maximization on moral dilemmas.

Childhood physical unpredictability. In the first step, religiosity and agreeableness each individually accounted for significant indirect variance between childhood physical unpredictability and the D parameter. Together in the same model, both agreeableness, $b=-.03$, $S E=.01, \mathrm{CI}_{95}[-.059,-.014]$ and religiosity, $b=.03, S E=.02, \mathrm{CI}_{95}[.002, .068]$ mediated the relationship between childhood physical unpredictability and deontological response tendencies in different directions. Effects were relatively weaker with the other Big 5 personality traits entered simultaneously: agreeableness, $b=-.02, S E=.01, \mathrm{CI}_{95}[-.051,-.005]$, religiosity, $b=.03$, $S E=.02, \mathrm{CI} 95[-.003, .068]$.

Only religiosity accounted for significant indirect variance between childhood physical unpredictability and the U parameter: $b=-.05, S E=.01, \mathrm{CI}_{95}[-.079,-.021]$. In sum, people who experienced more unpredictability in their physical environments were more religious, which was associated with higher levels of harm aversion and lower levels of outcome maximization. However, people from unpredictable environments were also less agreeable, which in turn predicted less harm aversion. 
Childhood harshness. None of the individual differences accounted for significant indirect variance between childhood physical unpredictability and the D or U parameters (see Supplemental Materials).

\section{Discussion}

Study 5 employed new extended measures designed to more fully capture the unpredictability and harshness of childhood environments. We replicated the finding of the five prior studies that people whose childhood ecologies were characterized by more unpredictability were less concerned about rejecting harm to and increasing overall wellbeing for others. Without controlling for other ecological factors and demographics, childhood harshness was not associated with either response tendency, replicating the first two studies: whether people lacked resources in childhood was unassociated with their moral dilemma decision making.

This study moved beyond the prior studies to include broader (beyond social) elements of childhood ecologies. When those nonsocial, physical features of the childhood environment were relatively unpredictable, people displayed less concern about harm aversion and outcome maximization. Social and physical unpredictability were highly correlated, such that people who reported experiencing high levels of social unpredictability also reported experiencing high levels of physical unpredictability. One possibility is that unreliable families, neighbors, and peers were more likely to inhabit or were at least unable to buffer children from more chaotic physical environments, such as changing neighborhood structure.

With respect to the role of religiosity, political conservativism, personality, and social desirability, regression analyses suggest the associations between ecological factors and moral decision making are robust to these potential confounds. Mediation analyses further suggest the possibility that two individual differences may fall in a causal chain linking early developmental 
ecological conditions to moral dilemma decision making in adulthood: agreeableness and religiosity. The more unpredictable people's childhood environments were, the less agreeable they tended to be, and this contributed to lower levels of harm aversion across moral dilemmas. This fits with other work that finds childhood unpredictability is associated with low agreeableness in adulthood (e.g., Chen et al., 2017), which may be an adaptive strategy to the extent that one cannot afford to invest in other people in an unpredictable environment (e.g., Del Giudice, 2016; Figueredo et al., 2007; Gladden et al., 2008).

Greater unpredictability was also associated with higher levels of religiosity, which contributed to less outcome maximizing across moral dilemmas. This pattern is consistent with research suggesting that religiosity serves as a buffer to the effects of challenging childhood ecologies (e.g., Henderson, 2016) but contrasts with work that suggests lower levels of religiosity are responses to early unpredictability (e.g., Gladden et al.., 2008, 2009). Moreover, prior work has similarly demonstrated that religiosity contributes to less outcome maximizing (e.g., Reynolds et al., 2019). Thus, over and above potential confounds, childhood unpredictability is linked with moral decisions in adulthood, although findings are also consistent with the possibility that this link might be at least partially mediated by agreeableness. 
Table 5

Correlations Among Variables, Study 5.

\begin{tabular}{|c|c|c|c|c|c|c|c|c|c|c|c|c|c|c|c|}
\hline & 1 & 2 & 3 & 4 & 5 & 6 & 7 & 8 & 9 & 10 & 11 & 12 & 13 & 14 & 15 \\
\hline $\begin{array}{l}\text { 1. Utilitarian PD } \\
\text { Parameter }\end{array}$ & - & & & & & & & & & & & & & & \\
\hline $\begin{array}{l}\text { 2. Deontology PD } \\
\text { Parameter }\end{array}$ & $.26^{* \star *}$ & - & & & & & & & & & & & & & \\
\hline $\begin{array}{l}\text { 3. Childhood Social } \\
\text { Unpredictability }\end{array}$ & $-.37^{* \star}$ & $-.42^{* * *}$ & - & & & & & & & & & & & & \\
\hline $\begin{array}{l}\text { 4. Childhood Physical } \\
\text { Unpredictability }\end{array}$ & $-.49^{* \star}$ & $-.47^{\star \star \star}$ & $.84^{\star \star \star}$ & - & & & & & & & & & & & \\
\hline $\begin{array}{l}\text { 5. Childhood } \\
\text { Harshness }\end{array}$ & .02 & -.06 & $.54^{\star \star \star}$ & $.36^{* * *}$ & - & & & & & & & & & & \\
\hline 6. Religiosity & $-.36^{* \star *}$ & -.07 & $.27^{* \star \star}$ & $.42^{* * *}$ & -.06 & - & & & & & & & & & \\
\hline $\begin{array}{l}\text { 7. Political } \\
\text { Conservativism }\end{array}$ & $-.27^{\star \star *}$ & $-.23^{\star *}$ & $.34^{\star \star \star}$ & $.41^{* * *}$ & .03 & $.53^{* * *}$ & - & & & & & & & & \\
\hline 8. Openness & .02 & .08 & .09 & .10 & -.00 & .07 & $-.12^{\dagger}$ & - & & & & & & & \\
\hline 9. Conscientiousness & $.15^{*}$ & $.30^{* \star *}$ & $-.31^{* \star *}$ & $-.19^{* *}$ & -.11 & $.12^{\dagger}$ & $-.12^{\dagger}$ & $.27^{\star \star \star *}$ & - & & & & & & \\
\hline 10. Extroversion & -.10 & $-.15^{\star}$ & $.16^{*}$ & $.20^{* *}$ & -.04 & $.16^{*}$ & .02 & $.21^{* *}$ & .05 & - & & & & & \\
\hline 11. Agreeableness & .09 & $.34^{\star \star \star}$ & $-.23^{* * *}$ & $-.24^{* * *}$ & -.05 & .03 & $-.16^{*}$ & $.30^{* * *}$ & $.53^{* * *}$ & .00 & - & & & & \\
\hline 12. Neuroticism & -.01 & $-.14^{\star}$ & $.22^{* *}$ & $.12^{\dagger}$ & $.26^{\star \star \star}$ & $-.30^{\star \star \star}$ & $-.20^{\star *}$ & .05 & $-.36^{* \star *}$ & $-.12^{\dagger}$ & $.21^{* *}$ & - & & & \\
\hline 13. Social Desirability & -.01 & $.25^{\star \star \star}$ & -.11 & -.02 & -.07 & $.22^{* *}$ & .10 & $.12^{\dagger}$ & $.29^{\star \star \star}$ & .07 & $.37^{* * *}$ & $-.34^{\star \star \star}$ & - & & \\
\hline 14. Adult income & -.02 & .01 & $-.13^{\dagger}$ & -.02 & $-.37^{\star \star \star}$ & $.17^{*}$ & .08 & $-.15^{\star}$ & .02 & .02 & -.04 & $-29^{\star \star \star}$ & .09 & - & \\
\hline 15. Gender $(f=1, m=2)$ & -.05 & -.11 & .08 & .10 & -.04 & .07 & $.16^{*}$ & $-.13^{\dagger}$ & -.04 & -.07 & $-.13^{\dagger}$ & $-.22^{* *}$ & -.06 & $.16^{*}$ & - \\
\hline 16. Age & -.07 & -.00 & .07 & $.14^{*}$ & -.04 & $.27^{* *}$ & $.23^{* *}$ & $-.13^{\dagger}$ & .07 & -.07 & -.01 & $-28^{* \star *}$ & .10 & $.18^{\star *}$ & $.19^{* *}$ \\
\hline
\end{tabular}

Note: ${ }^{\dagger} p<.10,{ }^{*} p<.05,{ }^{* *} p<.01,{ }^{* * *} p<.001$ 


\section{Meta-Analysis}

We conducted a meta-analysis across all six studies to quantify the effect of childhood social unpredictability and of childhood harshness on moral dilemma responses (for details and syntax see https://mason.gmu.edu/ dwilsonb/ma.html). Specifically, we conducted two random effects meta-analyses across all samples $(N=1,503)$, correcting for differences in sample sizes (Lipsey \& Wilson, 2001; Wilson, 2010). For unpredictability, there was a significant mediumsized effect of childhood unpredictability on the $\mathrm{U}$ parameter, $b=-.27, Z=-5.12, p<.001, \mathrm{CI}_{95}[-$ $.383,-.178]$, which varied in magnitude across studies, $Q(5)=25.07, p<.001$. Likewise, there was a significant medium effect of childhood unpredictability on the $\mathrm{D}$ parameter, $b=-.30, Z=$ $4.67, p<.001, \mathrm{CI}_{95}[-.408,-.175]$, which also varied in magnitude across studies, $Q(5)=32.83, p$ $<.001$.

Across these studies, there was no significant effect of childhood harshness on the $\mathrm{U}$ parameter, $b=.06, Z=1.29, p=.197, \mathrm{CI}_{95}[-.030, .145]$, but this effect varied in magnitude across studies, $Q(5)=15.64, p=.008$. Likewise, there was no significant effect of childhood harshness on the $\mathrm{D}$ parameter, $b=.06, Z=1.41, p=.160$, $\mathrm{CI}_{95}[-.022, .131]$, but this effect varied in magnitude across studies, $Q(5)=11.86, p=.037$. These high-powered meta-analytic results confirmed that childhood unpredictability, but not harshness, was associated with moral decision making, such that people who experienced unpredictable, versus predictable, childhoods were less concerned about harm to and maximization of outcomes for others on moral dilemmas.

\section{General Discussion}

Humans display remarkable phenotypic plasticity, developing flexibly to meet the demands of particular ecologies with different affordances (Sng et al., 2017). When faced with difficult childhood environments, people tend to develop in ways strategically aimed at helping 
them reap the benefits, and avoid the perils, of adverse ecologies. One important aspect of the ecology involves its predictability — can one forecast what resources and social support one will have in the future? Another important aspect of the ecology is harshness - does one have sufficient resources to survive?

Although both unpredictability and harshness encourage impulsivity in order to gain resources in the present (e.g., Griskevicius et al., 2011; Mittal \& Griskevicius, 2014), their downstream social effects diverge: unpredictability begets a focus on the self (versus others) whereas harshness begets a focus on others (versus self; e.g., Barbaro \& Shackelford, 2019; Belsky et al., 2012; Simpson et al., 2012; Stephens et al., 2007, 2011, 2012; Szepsenwol et al, 2019). The current work elucidated how exposure to unpredictability and harshness in childhood shapes a central aspect of social life - morality, namely in decisions to accept harm that may or may not improve others' wellbeing.

Across six studies, people exposed to childhood unpredictability were less inclined to avoid harm and maximize wellbeing, whereas harshness did not reliably predict dilemma judgments. Moreover, individual differences thought to comprise adaptive responses to early ecological uncertainty accounted for the link between childhood unpredictability and patterns of dilemma responses (Studies 4 and 5). Specifically, people who grew up in unpredictable environments experienced low levels of empathic concern and less supportive close relationships (Study 4) and evinced disagreeable personalities (Study 5), which contributed to less concern about avoiding harm to and increasing wellbeing for others.

Moving beyond a narrow focus on social environments, we also demonstrated that effects of childhood unpredictability extended to physical aspects of childhood environments (e.g., the weather, neighborhood structures; Study 5). Thus, whether unpredictability involved the 
uncertainty of social relationships or instabilities within neighborhood environments, experiencing unpredictability in childhood was associated with less avoidance of harm and maximization of wellbeing in social dilemmas. Notably, the association between childhood unpredictability and deontological and utilitarian responding held above and beyond potential confounds, including religiosity, political orientation, the Big 5 personality traits, and social desirability (Study 5) and childhood harshness (Studies 1-5). These findings fit with an emerging picture in the behavioral ecology literature that early childhood unpredictability rather than resource scarcity calibrates people's social strategies to deprioritize the interest of others (e.g., Barbaro \& Shackelford, 2019; Belsky et al., 2012; Simpson et al., 2012; Szepsenwol et al, 2019).

Finally, information about the current ecology's unpredictability of resources did not amplify the relationship between childhood unpredictability and deontological and utilitarian response tendencies (Studies 3a and 3b). This suggests that perhaps the processes underlying complex dilemma decisions are insensitive to immediate cues in the environment given the costs of flexibility to potentially transient changes in resource availability (see DeWitt et al., 1998).

\section{Theoretical Implications}

The current work extends a growing body of research suggesting that early childhood environments can profoundly shape behavior in adulthood (Belsky et al., 1991). Such work suggests that behavior is calibrated early in development to help people face adversity throughout the lifespan (Del Giudice et al., 2011). While previous work has tended to focus on implications of childhood environments for processes immediately tied to reproduction (e.g., mating and parenting; e.g., Simpson et al., 2012) and health (Ehrlich et al., 2016; McDade et al., 2010), the current work advances this literature by investigating implications for moral decision making. 
This research builds on prior work linking unpredictability and harshness with moral decisions. For example, prior work has demonstrated that both childhood unpredictability and harshness were associated with selfish decisions on adapted moral dilemmas (Zhu et al., 2018). However, those cases forced people to choose between incurring a cost to the self and making decisions consistent with deontological and utilitarian ethics. In contrast, we employed dilemmas in which harming one focal target benefits many other targets, thus disentangling harm-rejection and outcome-maximization responses. In doing so, our analysis reveals a different predictive pattern for childhood unpredictability versus harshness. Such a pattern underscores that these ecological factors are distinct and likely shape moral concerns in differentiable ways.

Other work suggests that neither childhood unpredictability nor harshness predict cooperation in behavioral economic games (Wu et al., 2017). However, cooperative decisions differ from sacrificial decisions in important ways. For one, sacrificial dilemmas entail possibilities to prevent harm to one or multiple parties, whereas cooperative decisions entail possibilities to improve outcomes for oneself or multiple parties - a psychology focused on moral prescriptions that most dilemma responses fail to capture (Kahane et al., 2018; Conway et al., 2018). Another difference is that humans have a strong norm of initial cooperation in situations that could benefit the self and in which the alternative is to forego the gamble for reward altogether, even when people privately feel distrusting (Baumard et al., 2013; Dunning et al., 2014). Conversely, there is less consensus about the optimal decision in moral dilemmas, where more than one moral imperative can be brought to bear. Future work is needed to clarify how exposure to unpredictable environments in early childhood impacts different types of moral considerations. 
The present work also adds to a growing body of literature demonstrating that moral dilemma judgments result from two separate preferences, one to avoid harm and one to maximize outcomes, rather than from a single preference that spans aversion to acceptance of harm. Indeed, if we had relied on conventional analyses that cast moral decisions as residing on a single continuum, it would have obscured the relationships with childhood unpredictability that we observed. Moreover, the current findings are informative regarding the psychological processes involved in sacrificial dilemmas. Although considerable evidence supports dual process claims that that harm-rejection judgments reflect emotional concern for victims and outcome-maximization judgments reflect cognitive evaluations of overall wellbeing (e.g., Greene, 2007), many other processes contribute as well (see Skitka \& Conway, 2018). Indeed, we found that other-focused variables, namely, empathic concern and close relationship quality partially account for the relationship between unpredictability and deontological and utilitarian response tendencies. That is, people who experienced relatively unpredictable childhood environments experienced less empathic concern and poorer quality close relationships, which in turn predicted less harm aversion and outcome maximization. This adds to a growing body of work suggesting that concern for others contributes to both deontological and utilitarian decisions (e.g., Conway et al., 2018).

\section{Limitations}

Sufficient power, preregistration, and replication increase confidence in the results reported here. Nonetheless, we also consider four key limitations. The first limitation is inherent to all moral dilemma research: interpretations of response patterns presuppose that participants accept a set of closed world assumptions (Bennis et al., 2010). Participants must accept that the harm described in the dilemma will bring about the desired outcomes and that there are no 
feasible alternative actions. For example, if participants believe that torturing the man who has planted a dangerous bomb will not lead to his reporting where it is and therefore saving many people, they may reject harming the man for utilitarian rather than deontological reasons. In a similar vein, moral decision making here reflects consideration of hypothetical rather than real dilemmas. Although dilemma judgments appear to reflect broader patterns of moral concerns (Conway et al., 2018), it remains possible that decisions on real dilemmas may differ from those described here (see Bostyn et al., 2018).

Second, like most dilemma work, the dilemmas employed in the current work examine violations of proscriptive norms - actions that harm others (Janoff-Bulman et al., 2009). No actions directly entail saving others from harm, consistent with prescriptive norms. Therefore, refusal to cause harm cannot be disentangled from general unwillingness to act, or tendency for inaction (Gawronski \& Beer, 2017; Gawronski et al., 2018; Crone \& Laham, 2017). Future research may benefit by examining how early environmental unpredictability shapes action versus inaction on moral dilemmas. To the extent that lower impulse control serves as an adaptive calibration to unpredictability (e.g., Griskevicius et al., 2011; Mittal \& Griskevicius, 2014), it is possible that people who experienced a relatively unpredictable early developmental environment would respond by acting, regardless of whether doing so causes or prevents harm.

Third, although Studies 3a and 3b included experimental manipulations of current unpredictability, these manipulations did not systematically impact sacrificial responses. Instead, we draw conclusions primarily from correlational data, which cannot speak to causation. Our data are not capable of showing that an unpredictable childhood environment causes people to reject harm and maximize outcomes less often on moral dilemmas. Manipulating childhood unpredictability, however, is neither ethical nor practical. Accordingly, future research may 
employ longitudinal designs to decipher whether unpredictability experiences precede lower deontological and utilitarian decision making.

Relatedly, the current studies cannot account for genetic factors, which likely play an important role in accounting for the link between childhood environments and adult outcomes (see Belsky, 2012). One major source of unpredictability in a person's childhood environment comes from close family members (with whom one shares a higher than average proportion of genes), such that genetic factors may confound the associations between observed phenotypic characteristics (e.g., Barbaro et al., 2017)—here, people's childhood ecology and moral dilemma judgments. It could be that people who are low in harm-aversion and outcome-maximizing tendencies lead more unpredictable lives, thereby exposing their children to increased unpredictability while also contributing genes that promote lower concerns about harm to and wellbeing of others. Indeed, research shows that genetic variability in serotonin transporter genes influence sacrificial decisions through variation in concern for others (e.g., Crockett et al., 2010). Hence, future research could employ behavioral genetic methods to examine the extent to which genetic versus environmental factors account for the link between unpredictability in childhood and moral decision making in adulthood.

Finally, our samples were drawn from largely WEIRD populations (Western, Educated, Industrialized, Rich, and Democratic; Henrich et al., 2010). Although we sought diversity in our samples by collecting data from both students and the broader population via Amazon's Mechanical Turk, which tends to reflect the demographics of America better than student samples (Huff \& Tingley, 2015), less than 30\% of our participants identified as non-White. Although some studies note considerable cross-cultural similarity in dilemma responding (Banerjee et al., 2010), others note some variability (e.g., Gold et al., 2014). Thus, we must 
exercise caution in generalizing results to other populations or cultures. Notably, groups' social strategies are sometimes calibrated to ecological demands that vary across nations (e.g., population density), as evidenced by work using data from Europe, Asia, Africa, North America, South America, and the Insular Pacific (Sng et al., 2017). Moreover, cultures vary with respect to self- versus other-focused norms: in interdependent, versus independent, cultures, people prioritize consideration of and acting for the group rather than the self (Markus \& Kitayama, 1991). Hence, one might expect that cultural factors such as population density or interdependence might amplify or buffer against effects of childhood adversity on moral decision making in adulthood.

\section{Conclusion}

Considerable research examines the proximate psychological processes underlying responses to sacrificial dilemmas in which causing harm saves lives, but little is known about how those processes are shaped by early developmental factors. In the current work, we applied a behavioral ecological framework to understand how early childhood experiences shape people's approach to morality in adulthood. Humans are sensitive to their early environments, which calibrate development in ways designed to facilitate survival and reproduction throughout lifespan. The current work is the first to demonstrate that early unpredictability and harshness have different downstream effects when it comes to a central aspect of social life-making moral decisions about harm to individuals and wellbeing of groups. People who experienced greater childhood unpredictability were less concerned about avoiding harm and maximizing outcomes, associations partly explained by a lack of empathy and close relationship support. In contrast, people who grew up with a dearth of resources were not more or less likely to reject harm or maximize outcomes than people who grew up with an abundance of resources. Hence, the 
current work moves beyond the how of moral dilemma decision making and underscores the why: If one is uncertain about what opportunities or challenges tomorrow will bring, one may be less inclined to rely on other-oriented forms of moral thinking, and therefore less inclined to avoid harm to and to maximize outcomes for other people. 


\section{References}

Adler, N. E., Boyce, W. T., Chesney, M. A., Folkman, S., \& Syme, S. L. (1993). Socioeconomic inequalities in health: no easy solution. JAMA, 269(24), 3140-3145.

Altemeyer, B. (1988). Enemies of freedom: Understanding right-wing authoritarianism. JosseyBass.

Amit, E., \& Greene, J. D. (2012). You see, the ends don't justify the means: Visual imagery and moral judgment. Psychological Science, 23, 861-868.

Baldini, R. (2015). Harsh environments and" fast" human life histories: What does the theory say? BioRxiv, 014647.

Banerjee, K., Huebner, B., \& Hauser, M. (2010). Intuitive moral judgments are robust across demographic variation in gender, education, politics, and religion: A largescale webbased study. Journal of Cognition and Culture, 10, 253-281.

Barbaro, N., \& Shackelford, T. K. (2019). Environmental unpredictability in childhood is associated with anxious romantic attachment and intimate partner violence perpetration. Journal of Interpersonal Violence, 34, 240-269.

Barbaro, N., \& Shackelford, T. K. (2019). Environmental unpredictability in childhood is associated with anxious romantic attachment and intimate partner violence perpetration. Journal of Interpersonal Violence, 34(2), 240-269.

Barbaro, N., Boutwell, B. B., Barnes, J. C., \& Shackelford, T. K. (2017). Genetic confounding of the relationship between father absence and age at menarche. Evolution and Human Behavior, 38(3), 357-365.

Baron, J., Gürçay, B., Moore, A. B., \& Starcke, K. (2012). Use of a Rasch model to predict response times to utilitarian moral dilemmas. Synthese, 189, 107-117. 
Bartels, D. M. (2008). Principled moral sentiment and the flexibility of moral judgment and decision-making. Cognition, 108, 381-417. doi:10.1016/j.cognition.2008.03.001

Baumard, N., André, J. B., \& Sperber, D. (2013). A mutualistic approach to morality: The evolution of fairness by partner choice. Behavioral and Brain Sciences, 36, 59-78.

Belsky, J., Schlomer, G. L., \& Ellis, B. J. (2012). Beyond cumulative risk: distinguishing harshness and unpredictability as determinants of parenting and early life history strategy. Developmental Psychology, 48(3), 662.

Belsky, J., Schlomer, G. L., \& Ellis, B. J. (2012). Beyond cumulative risk: distinguishing harshness and unpredictability as determinants of parenting and early life history strategy. Developmental Psychology, 48(3), 662.

Belsky, J., Steinberg, L., \& Draper, P. (1991). Childhood experience, interpersonal development, and reproductive strategy: An evolutionary theory of socialization. Child Development, $62,647-670$.

Belsky, J., Steinberg, L., \& Draper, P. (1991). Childhood experience, interpersonal development, and reproductive strategy: An evolutionary theory of socialization. Child development, $62(4), 647-670$.

Bennis, W. M., Medin, D. L., \& Bartels, D. M. (2010). The costs and benefits of calculation and moral rules. Perspectives on Psychological Science, 5, 187-202.

Bostyn, D. H., Sevenhant, S., \& Roets, A. (2018). Of mice, men, and trolleys: Hypothetical judgment versus real-life behavior in trolley-style moral dilemmas. Psychological Science, 29, 1084-1093. 
Brumbach, B. H., Figueredo, A. J., \& Ellis, B. J. (2009). Effects of harsh and unpredictable environments in adolescence on development of life history strategies: A longitudinal test of an evolutionary model. Human Nature, 20, 25-51.

Brumbach, B. H., Figueredo, A. J., \& Ellis, B. J. (2009). Effects of harsh and unpredictable environments in adolescence on development of life history strategies. Human Nature, $20(1), 25-51$

Byrd, N., \& Conway, P. (2019). Not all who ponder count costs: Arithmetic reflection predicts utilitarian tendencies, but logical reflection predicts both deontological and utilitarian tendencies. Cognition, 192, 103995.

Carlo, G., Koller, S. H., Eisenberg, N., Da Silva, M. S., \& Frohlich, C. B. (1996). A crossnational study on the relations among prosocial moral reasoning, gender role orientations, and prosocial behaviors. Developmental Psychology, 32, 231-240.

Chen, B. B. (2018). An evolutionary life history approach to understanding greed. Personality and Individual Differences, 127, 74-78.

Chen, B. B., Shi, Z., \& Sun, S. (2017). Life history strategy as a mediator between childhood environmental unpredictability and adulthood personality. Personality and Individual Differences, 111, 215-219.

Chisholm, J. S., Quinlivan, J. A., Petersen, R. W., \& Coall, D. A. (2005). Early stress predicts age at menarche and first birth, adult attachment, and expected lifespan. Human Nature, 16, 233-265.

Chisholm, J. S., Quinlivan, J. A., Petersen, R. W., \& Coall, D. A. (2005). Early stress predicts age at menarche and first birth, adult attachment, and expected lifespan. Human Nature, $16(3), 233-265$. 
Conway, P., \& Gawronski, B. (2013). Deontological and utilitarian inclinations in moral decision-making: a process dissociation approach. Journal of Personality and Social Psychology, 104, 216-235.

Conway, P., \& Gawronski, B. (2013). Deontological and utilitarian inclinations in moral decision making: a process dissociation approach. Journal of Personality and Social Psychology, 104(2), 216.

Conway, P., Goldstein-Greenwood, J., Polacek, D., \& Greene, J. D. (2018). Sacrificial utilitarian judgments do reflect concern for the greater good: Clarification via process dissociation and the judgments of philosophers. Cognition, 179, 241-265.

Conway, P., Goldstein-Greenwood, J., Polacek, D., \& Greene, J. D. (2018). Sacrificial utilitarian judgments do reflect concern for the greater good: Clarification via process dissociation and the judgments of philosophers. Cognition, 179, 241-265.

Conway, P., Weiss, A., Burgmer, P., \& Mussweiler, T. (2018). Distrusting your moral compass: The impact of distrust mindsets on moral dilemma processing and judgments. Social Cognition, 36(3), 345-380.

Copping, L. T., Campbell, A., \& Muncer, S. (2014). Psychometrics and life history strategy: The structure and validity of the high K strategy scale. Evolutionary Psychology, 12(1), 147470491401200115 .

Crockett, M. J., Clark, L., Hauser, M. D., \& Robbins, T. W. (2010). Serotonin selectively influences moral judgment and behavior through effects on harm aversion. Proceedings of the National Academy of Sciences, 107, 17433-17438. 
Crone, D. L., \& Laham, S. M. (2017). Utilitarian preferences or action preferences? Deconfounding action and moral code in sacrificial dilemmas. Personality and Individual Differences, 104, 476-481.

Damian, R. I., \& Sherman, J. W. (2013). A process-dissociation examination of the cognitive processes underlying unconscious thought. Journal of Experimental Social Psychology, $49(2), 228-237$.

Davis, M. H. (1983). Measuring individual differences in empathy: Evidence for a multidimensional approach. Journal of Personality and Social Psychology, 44, 113-126.

Del Giudice, M. (2016). The life history model of psychopathology explains the structure of psychiatric disorders and the emergence of the p factor: a simulation study. Clinical Psychological Science, 4(2), 299-311.

Del Giudice, M., Ellis, B. J., \& Shirtcliff, E. A. (2011). The Adaptive Calibration Model of stress responsivity. Neuroscience \& Biobehavioral Reviews, 35, 1562-1592.

DeWitt, T. J., Sih, A., \& Wilson, D. S. (1998). Costs and limits of phenotypic plasticity. Trends in Ecology \& Evolution, 13, 77-81.

Dingemanse, N. J., Both, C., Drent, P. J., \& Tinbergen, J. M. (2004). Fitness consequences of avian personalities in a fluctuating environment. Proceedings of the Royal Society B, $271,847-852$.

Doom, J. R., Vanzomeren-Dohm, A. A., \& Simpson, J. A. (2016). Early unpredictability predicts increased adolescent externalizing behaviors and substance use: A life history perspective. Development and Psychopathology, 28, 1505-1516. 
Doom, J. R., Vanzomeren-Dohm, A. A., \& Simpson, J. A. (2016). Early unpredictability predicts increased adolescent externalizing behaviors and substance use: A life history perspective. Development and Psychopathology, 28, 1505-1516.

Dunkel, C. S., Mathes, E., \& Beaver, K. M. (2013). Life history theory and the general theory of crime: Life expectancy effects on low self-control and criminal intent. Journal of Social, Evolutionary, and Cultural Psychology, 7(1), 12.

Dunning, D., Anderson, J. E., Schlösser, T., Ehlebracht, D., \& Fetchenhauer, D. (2014). Trust at zero acquaintance: More a matter of respect than expectation of reward. Journal of Personality and Social Psychology, 107, 122-141. doi:10.1037/a0036673

Ehrlich, K. B., Miller, G. E., \& Chen, E. (2016). Childhood adversity and adult physical health. Developmental Psychopathology, 22, 1-42.

Eisenberg, N. (1986). Altruistic emotion, cognition, and behavior. Hillsdale, NJ: Erlbaum.

Ellis, B. J., \& Del Giudice, M. (2019). Developmental adaptation to stress: An evolutionary perspective. Annual Review of Psychology, 70, 111-139.

Ellis, B. J., Figueredo, A. J., Brumbach, B. H., \& Schlomer, G. L. (2009). Fundamental dimensions of environmental risk: The impact of harsh versus unpredictable environments on the evolution and development of life history strategies. Human Nature, 20, 204-268.

Ellis, B. J., Figueredo, A. J., Brumbach, B. H., \& Schlomer, G. L. (2009). Fundamental dimensions of environmental risk. Human Nature, 20(2), 204-268.

Faul, F., Erdfelder, E., Lang, A. ,G., \& Buchner, A. (2007). GPower 3: A flexible statistical power analysis program for the social, behavioral, and biomedical sciences. Behavior Research Methods, 39, 175-191. doi:10.3758/BF03193146 
Ferreira, M. B., Garcia-Marques, L., Sherman, S. J., \& Sherman, J. W. (2006). Automatic and controlled components of judgment and decision making. Journal of Personality and Social Psychology, 91(5), 797.

Figueredo, A. J., \& Jacobs, W. J. (2010). Aggression, risk-taking, and alternative life history strategies: The behavioral ecology of social deviance. Bio-psychosocial perspectives on interpersonal violence, 3-28.

Figueredo, A. J., Andrzejczak, D. J., Jones, D. N., Smith-Castro, V. \& Montero, E. (2011). Reproductive strategy and ethnic conflict: Slow life history as a protective factor against negative ethnocentrism in two contemporary societies. Journal of Social, Evolutionary, and Cultural Psychology, 5(1), 14-31.

Figueredo, A. J., Andrzejczak, D. J., Jones, D. N., Smith-Castro, V., \& Montero, E. (2011). Reproductive strategy and ethnic conflict: Slow life history as a protective factor against negative ethnocentrism in two contemporary societies. Journal of Social, Evolutionary, and Cultural Psychology, 5(1), 14.

Figueredo, A. J., Garcia, R. A., Menke, J. M., Jacobs, W. J., Gladden, P. R., Bianchi, J., ... \& Jiang, Y. (2017). The K-SF-42: A new short form of the Arizona Life History Battery. Evolutionary Psychology, 15(1), 1474704916676276.

Figueredo, A. J., Jacobs, W. J., Gladden, P. R., Bianchi, J., Patch, E. A., Kavanagh, P. S., ... \& Li, N. P. (2018). Intimate partner violence, interpersonal aggression, and life history strategy. Evolutionary Behavioral Sciences, 12, 1-31.

Figueredo, A. J., Vasquez, G., Brumbach, B. H., \& Schneider, S. M. (2004). The heritability of life history strategy: The k-factor, covitality, and personality. Social Biology, 51(3-4), $121-143$. 
Figueredo, A. J., Vásquez, G., Brumbach, B. H., \& Schneider, S. M. (2007). The K-factor, covitality, and personality. Human Nature, 18, 47-73.

Figueredo, A. J., Vásquez, G., Brumbach, B. H., Schneider, S. M., Sefcek, J. A., Tal, I. R., ... \& Jacobs, W. J. (2006). Consilience and life history theory: From genes to brain to reproductive strategy. Developmental Review, 26(2), 243-275.

Figueredo, A. J., Vásquez, G., Brumbach, B. H., Sefcek, J. A., Kirsner, B. R., \& Jacobs, W. J. (2005). The K-factor: Individual differences in life history strategy. Personality and individual differences, 39(8), 1349-1360.

Fiske, S. T., \& Markus, H. R. (2012). A wide angle lens on the psychology of social class. In S. T. Fiske \& H. R. Markus (Eds.), Facing social class: Social psychology of social class. New York, NY: Russell Sage.

Fleischmann, A., Lammers, J., Conway, P., \& Galinsky, A. D. (2019). Paradoxical effects of power on moral thinking: why power both increases and decreases deontological and utilitarian moral decisions. Social Psychological and Personality Science, 10, 110-120.

Foot, P. (1967). The problem of abortion and the doctrine of double effect. Oxford Review, 5, 515

Friesdorf, R., Conway, P., \& Gawronski, B. (2015). Gender differences in responses to moral dilemmas: A process dissociation analysis. Personality and Social Psychology Bulletin, 41(5), 696-713.

Fritz, M. S., \& MacKinnon, D. P. (2007). Required sample size to detect the mediated effect. Psychological Science, 18, 233-239.

Furman, W., \& Buhrmester, D. (1985). Children's perceptions of the personal relationships in their social networks. Developmental Psychology, 21, 1016. 
Gamez-Djokic, M., \& Molden, D. (2016). Beyond affective influences on deontological moral judgment: The role of motivations for prevention in the moral condemnation of harm. Personality and Social Psychology Bulletin, 42(11), 1522-1537.

Gawronski, B., \& Beer, J. S. (2017). What makes moral dilemma judgments "utilitarian” or “deontological”? Social Neuroscience, 12, 626-632.

Gawronski, B., Conway, P., Armstrong, J., Friesdorf, R., \& Hütter, M. (2018). Effects of incidental emotions on moral dilemma judgments: An analysis using the CNI model. Emotion, 18, 989-1008.

Gladden, P. R., \& Cleator, A. M. (2017). Slow life history strategy predicts six moral foundations. Law and Human Behavior.

Gladden, P. R., Figueredo, A. J., \& Jacobs, W. J. (2008). Life history strategy, psychopathic attitudes, personality, and general intelligence. Personality and Individual Differences, $46,270-275$.

Gladden, P. R., Welch, J., Figueredo, A. J., \& Jacobs, W. J. (2009). Moral intuitions and religiosity as spuriously correlated life history traits. Journal of Evolutionary Psychology, 7(2), 167-184.

Gladden, P. R., Welch, J., Figueredo, A. J., \& Jacobs, W. J. (2009). Moral intuitions and religiosity as spuriously correlated life history traits. Journal of Evolutionary Psychology, $7(2), 167-184$.

Gold, N., Colman, A. M., \& Pulford, B. D. (2014). Cultural differences in responses to real-life and hypothetical trolley problems. Judgment and Decision-making, 9, 65-76.

Greene, J. D. (2007). Why are VMPFC patients more utilitarian? A dual-process theory of moral judgment explains. Trends in Cognitive Sciences, 11, 322-323. 
Greene, J. D. (2013). Moral tribes: Emotion, reason, and the gap between us and them. Penguin: London, England.

Greene, J. D., Nystrom, L. E., Engell, A. D., Darley, J. M., \& Cohen, J. D. (2004). The neural bases of cognitive conflict and control in moral judgment. Neuron, 44, 389-400. doi:10.1016/j.neuron.2004.09.027

Greene, J. D., Sommerville, R. B., Nystrom, L. E., Darley, J. M., \& Cohen, J. D. (2001). An fMRI investigation of emotional engagement in moral judgment. Science, 293, 21052108. doi:10.1126/science. 1062872

Griskevicius, V., Tybur, J. M., Delton, A. W., \& Robertson, T. E. (2011). The influence of mortality and socioeconomic status on risk and delayed rewards: a life history theory approach. Journal of Personality and Social Psychology, 100(6), 1015.

Grossmann, I., \& Varnum, M. E. (2011). Social class, culture, and cognition. Social Psychological and Personality Science, 2(1), 81-89.

Gruijters, S. L., \& Fleuren, B. P. (2018). Measuring the unmeasurable. Human Nature, 29(1), 3344.

Hahn, E., Gottschling, J., \& Spinath, F. M. (2012). Short measurements of personality-Validity and reliability of the GSOEP Big Five Inventory (BFI-S). Journal of Research in Personality, 46(3), 355-359.

Haidt, J., \& Hersh, M. A. (2001). Sexual morality: The cultures and emotions of conservatives and liberals 1. Journal of Applied Social Psychology, 31(1), 191-221.

Hayakawa, S., Tannenbaum, D., Costa, A., Corey, J. D., \& Keysar, B. (2017). Thinking more or feeling less? Explaining the foreign-language effect on moral judgment. Psychological Science, 28(10), 1387-1397. 
Heaven, P. (1983). Authoritarianism or acquiescence? South African findings. Journal of Social Psychology, 119, 11-15.

Henderson, A. K. (2016). The long arm of religion: Childhood adversity, religion, and selfperception among Black Americans. Journal for the Scientific Study of Religion, 55(2), 324-348.

Henrich, J., Heine, S. J., \& Norenzayan, A. (2010). Beyond WEIRD: Towards a broad-based behavioral science. Behavioral and Brain Sciences, 33, 111-135.

Huff, C., \& Tingley, D. (2015). "Who are these people?" Evaluating the demographic characteristics and political preferences of MTurk survey respondents. Research \& Politics, 2, 2053168015604648.

Jacoby, L. L. (1991). A process dissociation framework: Separating automatic from intentional uses of memory. Journal of Memory and Language, 30(5), 513-541.

Janoff-Bulman, R., Sheikh, S., \& Hepp, S. (2009). Proscriptive versus prescriptive morality: Two faces of moral regulation. Journal of personality and social psychology, 96, 521.

Jonason, P. K., Icho, A., \& Ireland, K. (2016). Resources, harshness, and unpredictability: the socioeconomic conditions associated with the Dark Triad traits. Evolutionary Psychology, 14, 1474704915623699.

Jonason, P. K., Zeigler-Hill, V., \& Okan, C. (2017). Good v. evil: Predicting sinning with dark personality traits and moral foundations. Personality and Individual Differences, 104, 180-185.

Kahane, G., Everett, J. A., Earp, B. D., Caviola, L., Faber, N. S., Crockett, M. J., \& Savulescu, J. (2018). Beyond sacrificial harm: A two-dimensional model of utilitarian psychology. Psychological Review, 125, 131. 
Kahane, G., Everett, J. A., Earp, B. D., Farias, M., \& Savulescu, J. (2015). 'Utilitarian’ judgments in sacrificial moral dilemmas do not reflect impartial concern for the greater good. Cognition, 134, 193-209.

Kahane, G., Everett, J. A., Earp, B. D., Farias, M., \& Savulescu, J. (2015). 'Utilitarian'judgments in sacrificial moral dilemmas do not reflect impartial concern for the greater good. Cognition, 134, 193-209.

Kant, I. (1785). Groundwork of the Metaphysics of Morals.

Kant, I. (1959). Foundation of the metaphysics of morals (L. W. Beck, Trans.). Indianapolis, IN: Bobbs-Merrill. (Original work published 1785)

Koenigs, M., Young, L., Adolphs, R., Tranel, D., Cushman, F., Hauser, M., \& Damasio, A. (2007). Damage to the prefrontal cortex increases utilitarian moral judgments. Nature, 446, 908-911. doi:10.1038/Nature05631

Koenigs, M., Young, L., Adolphs, R., Tranel, D., Cushman, F., Hauser, M., \& Damasio, A. (2007). Damage to the prefrontal cortex increases utilitarian moral judgments. Nature, 446, 908-911. doi:10.1038/Nature05631

Lamont, M. (2000). The dignity of working men. New York, NY: Harvard University Press.

Lang, F. R., John, D., Lüdtke, O., Schupp, J., \& Wagner, G. G. (2011). Short assessment of the Big Five: Robust across survey methods except telephone interviewing. Behavior Research Methods, 43(2), 548-567.

Maranges, H. M., Chen, S., \& Conway, P. (2020). Too avoidant to avoid harm: Insecure attachment shapes moral dilemma judgments. Manuscript submitted for publication.

Maranges, H. M., Chen, S., \& Conway, P. (2020a). Too avoidant to avoid harm: Insecure attachment shapes moral dilemma judgments. Manuscript submitted for publication. 
Maranges, H. M., Reynolds, T. A., March, D. S., Baumeister, R. F., \& Conway, P. J. (2020b). Self-control as the moral dilemma muscle: Trait self-control predicts both deontological and utilitarian moral judgments. Manuscript submitted for publication.

Markus, H. R., \& Kitayama, S. (1991). Culture and the self: Implications for cognition, emotion, and motivation. Psychological Review, 98, 224-253.

Markus, H. R., Ryff, C. D., Curhan, K. B., \& Palmersheim, K. A. (2004). In their own words: Well-being at midlife among high school-educated and college-educated adults. How healthy are we, 273-319.

Marsh, H. W. (1986). Negative item bias in ratings scales for preadolescent children: A cognitive-developmental phenomenon. Developmental Psychology, 22, 37-49. doi:10.1037/0012-1649.22.1.37

Marsh, H. W. (1996). Positive and negative global self-esteem: A substantively meaningful distinction or artifactors? Journal of Personality and Social Psychology, 70, 810-819. doi:10.1037/0022-3514.70.4.810

McAdams, D. P., Reynolds, J., Lewis, M., Patten, A. H., \& Bowman, P. J. (2001). When bad things turn good and good things turn bad: Sequences of redemption and contamination in life narrative and their relation to psychosocial adaptation in midlife adults and in students. Personality and Social Psychology Bulletin, 27, 474-485.

McDade, T. W., Rutherford, J., Adair, L., \& Kuzawa, C. W. (2010). Early origins of inflammation: microbial exposures in infancy predict lower levels of C-reactive protein in adulthood. Proceedings of the Royal Society B: Biological Sciences, 277(1684), 11291137. 
McPhetres, J., Conway, P., Hughes, J. S., \& Zuckerman, M. (2018). Reflecting on God's will: Reflective processing contributes to religious peoples' deontological dilemma responses. Journal of Experimental Social Psychology, 79, 301-314.

Mill, J. S. (1861). Considerations on representative democracy. Parker, son and Bourn, London. Mill, J. S. (1998). Utilitarianism (R. Crisp, Ed.). New York, NY: Oxford University Press. (Original work published 1861)

Mittal, C., \& Griskevicius, V. (2014). Sense of control under uncertainty depends on people's childhood environment: A life history theory approach. Journal of Personality and Social Psychology, 107, 621.

Mittal, C., \& Griskevicius, V. (2014). Sense of control under uncertainty depends on people’s childhood environment: A life history theory approach. Journal of Personality and Social Psychology, 107(4), 621.

Mittal, C., Griskevicius, V., Simpson, J. A., Sung, S., \& Young, E. S. (2015). Cognitive adaptations to stressful environments: When childhood adversity enhances adult executive function. Journal of Personality and Social Psychology, 109, $604-621$. http://dx.doi.org/10.1037/pspi0000028

Mittal, C., Griskevicius, V., Simpson, J. A., Sung, S., \& Young, E. S. (2015). Cognitive adaptations to stressful environments: When childhood adversity enhances adult executive function. Journal of Personality and Social Psychology, 109(4), 604.

Moore, A. B., Clark, B. A., \& Kane, M. J. (2008). Who shalt not kill? Individual differences in working memory capacity, executive control, and moral judgment. Psychological Science, 19, 549-557. doi:10.1111/J.1467-9280.2008.02122.x 
Muda, R., Niszczota, P., Bialek, M., \& Conway, P. (2017). Reading dilemmas in a foreign language reduces both deontological and utilitarian response tendencies. Journal of Experimental Psychology: Learning, Memory, \& Cognition, 44, 321-326. doi: $10.1037 / \mathrm{xlm} 0000447$

Muda, R., Niszczota, P., Bialek, M., \& Conway, P. (2017). Reading dilemmas in a foreign language reduces both deontological and utilitarian response tendencies. Journal of Experimental Psychology: Learning, Memory, \& Cognition, 44, 321-326. doi: $10.1037 / x \operatorname{lm} 0000447$

Nettle, D. (2018). Hanging on to the Edges: Essays on Science, Society and the Academic Life. Is it Explanation Yet?

Neuberg, S. L., Kenrick, D. T., \& Schaller, M. (2010). Evolutionary social psychology. In S. T. Fiske, D. T. Gilbert, \& G. Lindzey (Eds.), Handbook of social psychology (5th ed., Vol. 2, pp. 761-796). New York, NY: Wiley. doi:10.1002/9780470561119.socpsy002021

Nichols, S., \& Mallon, R. (2006). Moral dilemmas and moral rules. Cognition, 100, 530-542.

Olderbak, S., \& Figueredo, A. J. (2009). Predicting romantic relationship satisfaction from life history strategy. Personality and Individual Differences, 46(5-6), 604-610.

Oppenheimer, D. M., Meyvis, T., \& Davidenko, N. (2009). Instructional manipulation checks: Detecting satisficing to increase statistical power. Journal of Experimental Social Psychology, 45, 867-872. doi:10.1016/j.jesp.2009.03.009

Patil, I., \& Silani, G. (2014). Reduced empathic concern leads to utilitarian moral judgments in trait alexithymia. Frontiers in psychology, 5, 501.

Payne, B. K. (2001). Prejudice and perception: the role of automatic and controlled processes in misperceiving a weapon. Journal of Personality and Social Psychology, 81(2), 181. 
Payne, B. K., \& Bishara, A. J. (2009). An integrative review of process dissociation and related models in social cognition. European Review of Social Psychology, 20(1), 272-314.

Pepper, G. V., \& Nettle, D. (2017). The behavioral constellation of deprivation: Causes and consequences. Behavioral and Brain Sciences, 40.

Pepper, G. V., \& Nettle, D. (2017). The behavioral constellation of deprivation: Causes and consequences. Behavioral and Brain Sciences, 40 .

Petrinovich, L., \& O’Neill, P. (1996). Influence of wording and framing effects on moral intuitions. Ethology \& Sociobiology, 17, 145-171.

Petrinovich, L., O’Neill, P., \& Jorgensen, M. (1993). An empirical study of moral intuitions: Toward an evolutionary ethics. Journal of Personality and Social Psychology, 64, 467478.

Pigliucci, M. (2005). Evolution of phenotypic plasticity: where are we going now? Trends in ecology \& evolution, 20, 481-486.

Pratt, H. (1993). Herons and egrets of Audubon Canyon Ranch. Self-published, available at Audubon Canyon Ranch, Stinson Beach, CA 94970.

Preacher, K. J., \& Hayes, A. F. (2004). SPSS and SAS procedures for estimating indirect effects in simple mediation models. Behavior Research Methods, 36, 717-731.

Ray, J. J. (1979). Is the acquiescent response style problem not so mythical after all? Some results from a successful balanced F scale. Journal of Personality Assessment, 43(6), $638-643$.

Ray, J. J. (1983). Reviving the problem of the acquiescent response bias. Journal of Social Psychology, 121, 81-96. 
Reynolds, C. J., \& Conway, P. (2018). Not just bad actions: Affective concern for bad outcomes contributes to moral condemnation of harm in moral dilemmas. Emotion, 18, 1009-1023. doi:10.1037/emo0000413

Reynolds, C. J., \& Conway, P. (2018). Not just bad actions: Affective concern for bad outcomes contributes to moral condemnation of harm in moral dilemmas. Emotion, 18(7), 1009.

Reynolds, C. J., Knighten, K. R., \& Conway, P. (2019). Mirror, mirror, on the wall, who is deontological? Completing moral dilemmas in front of mirrors increases deontological but not utilitarian response tendencies. Cognition, 192, 103993.

Reynolds, W. M. (1982). Development of reliable and valid short forms of the Marlowe-Crowne Social Desirability Scale. Journal of Clinical Psychology, 38(1), 119-125.

Richardson, G. B., Sanning, B. K., Lai, M. H., Copping, L. T., Hardesty, P. H., \& Kruger, D. J. (2017). On the psychometric study of human life history strategies: State of the science and evidence of two independent dimensions. Evolutionary Psychology, 15(1), 1474704916666840 .

Roff, D. (2002). Life history evolution. Sunderland, MA: Sinauer.

\section{Rom \& Conway, 2018***}

Royauté, R., Berdal, M. A., Garrison, C. R., \& Dochtermann, N. A. (2018). Paceless life? A meta-analysis of the pace-of-life syndrome hypothesis. Behavioral Ecology and Sociobiology, 72(3), 64.

Royzman, E. B., Landy, J. F., \& Leeman, R. F. (2015). Are thoughtful people more utilitarian? CRT as a unique predictor of moral minimalism in the dilemmatic context. Cognitive science, 39(2), 325-352. 
Rushton, J. P., \& Whitney, G. (2002). Cross-national variation in violent crime rates: Race, rK theory, and income. Population and Environment, 23(6), 501-511.

Schmitt, N., \& Stults, D. M. (1985). Factors defined by negatively keyed items: The result of careless respondents? Applied Psychological Measurement, 9, 367-373. doi:10.1177/014662168500900405

Simpson, J. A., Griskevicius, V., Kuo, S. I., Sung, S., \& Collins, W. A. (2012). Evolution, stress, and sensitive periods: the influence of unpredictability in early versus late childhood on sex and risky behavior. Developmental Psychology, 48, 674.

Simpson, J. A., Griskevicius, V., Kuo, S. I., Sung, S., \& Collins, W. A. (2012). Evolution, stress, and sensitive periods: the influence of unpredictability in early versus late childhood on sex and risky behavior. Developmental Psychology, 48(3), 674.

Skitka, L. J., \& Conway, P. (2018). Morality. In E. J. Finkle \& R. Baumeister (Eds.). Advanced Social Psychology: The State of The Science, Second Edition.

Sng, O., Neuberg, S. L., Varnum, M. E., \& Kenrick, D. T. (2017). The crowded life is a slow life: Population density and life history strategy. Journal of Personality and Social Psychology, 112, 736-754.

Sng, O., Neuberg, S. L., Varnum, M. E., \& Kenrick, D. T. (2018). The behavioral ecology of cultural psychological variation. Psychological Review, 125(5), 714.

Stephens, N. M., Fryberg, S. A., \& Markus, H. R. (2011). When choice does not equal freedom: A sociocultural analysis of agency in working-class American contexts. Social Psychological \& Personality Science, 2, 33-41. https://doiorg.proxy.lib.fsu.edu/10.1177/1948550610378757 
Stephens, N. M., Fryberg, S. A., Markus, H. R., Johnson, C. S., \& Covarrubias, R. (2012).

Unseen disadvantage: How American universities' focus on independence undermines the academic performance of first-generation college students. Journal of Personality and Social Psychology, 102(6), 1178-1197. doi:10.1037/a0027143

Stephens, N. M., Markus, H. R., \& Townsend, S. M. (2007). Choice as an act of meaning: The case of social class. Journal of Personality and Social Psychology, 93, 814-830. https://doi-org.proxy.lib.fsu.edu/10.1037/0022-3514.93.5.814

Strohminger, N., Lewis, R. L., \& Meyer, D. E. (2011). Divergent effects of different positive emotions on moral judgment. Cognition, 119, 295-300.

doi:10.1016/j.cognition.2010.12.012

Sugiyama, L. S. (2004). Illness, injury, and disability among Shiwiar forager-horticulturalists: Implications of health-risk buffering for the evolution of human life history. American Journal of Physical Anthropology: The Official Publication of the American Association of Physical Anthropologists, 123, 371-389.

Szepsenwol, O., Zamir, O., \& Simpson, J. A. (2019). The effect of early-life harshness and unpredictability on intimate partner violence in adulthood: A life history perspective. Journal of Social and Personal Relationships, 36, 1542-1556.

Szepsenwol, O., Zamir, O., \& Simpson, J. A. (2019). The effect of early-life harshness and unpredictability on intimate partner violence in adulthood: A life history perspective. Journal of Social and Personal Relationships, 36(5), 1542-1556.

Tomás, J. M., \& Oliver, A. (1999). Rosenberg's Self-Esteem Scale: Two factors or method effects. Structural Equation Modeling, 6, 84-98. doi:10.1080/10705519909540120 
Valdesolo, P., \& DeSteno, D. (2006). Manipulations of emotional context shape moral judgment. Psychological Science, 17, 476-477. Doi: 10.1111/j.1467-9280.2006.01731.x

Vohs, K. D., Mead, N. L., \& Goode, M. R. (2006). The psychological consequences of money. Science, 314, 1154-1156.

Weijters, B., Baumgartner, H., \& Schillewaert, N. (2013). Reversed item bias: An integrative model. Psychological Methods, 18, 320-334.

West-Eberhard, M. J. (1989). Phenotypic plasticity and the origins of diversity. Annual review of Ecology and Systematics, 20, 249-278.

Wilson, D. B. (August 11, 2010). Meta-analysis macros for SAS, SPSS, and Stata. Retrieved, December 6, 2017, from http://mason.gmu.edu/ dwilsonb/ma.html

Woods, C. M. (2006). Careless responding to reverse-worded items: Implications for confirmatory factor analysis. Journal of Psychopathology and Behavioral Assessment, 28, 189-194. doi:10.1007/s10862-005-9004-7

Wu, J., Balliet, D., Tybur, J. M., Arai, S., Van Lange, P. A., \& Yamagishi, T. (2017). Life history strategy and human cooperation in economic games. Evolution and Human Behavior, 38, 496-505.

Xu, Y., Norton, S., \& Rahman, Q. (2018). Early life conditions, reproductive and sexualityrelated life history outcomes among human males: A systematic review and metaanalysis. Evolution and Human Behavior, 39, 40-51.

Xu, Y., Norton, S., \& Rahman, Q. (2018). Early life conditions, reproductive and sexualityrelated life history outcomes among human males: A systematic review and metaanalysis. Evolution and Human Behavior, 39(1), 40-51. 
Yamagishi, T., \& Yamagishi, M. (1994). Trust and commitment in the United States and Japan. Motivation and Emotion, 18, 129-166.

Young, E. S., Griskevicius, V., Simpson, J. A., Waters, T. E., \& Mittal, C. (2018). Can an unpredictable childhood environment enhance working memory? Testing the sensitizedspecialization hypothesis. Journal of Personality and Social Psychology, 114, 891.

Young, E. S., Griskevicius, V., Simpson, J. A., Waters, T. E., \& Mittal, C. (2018). Can an unpredictable childhood environment enhance working memory? Testing the sensitizedspecialization hypothesis. Journal of Personality and Social Psychology, 114(6), 891.

Zhu, N., Hawk, S. T., \& Chang, L. (2018). Living Slow and Being Moral. Human Nature, 29, 186-209.

Zhu, N., Hawk, S. T., \& Chang, L. (2019). Unpredictable and competitive cues affect prosocial behaviors and judgments. Personality and Individual Differences, 138, 203-211.

Zietsch, B. P., \& Sidari, M. J. (2019). A critique of life history approaches to human trait covariation. Evolution and Human Behavior. 